\title{
Description of the Risø Puff Diffusion Model
}

\section{Mikkelsen, Torben}

Publication date:

1982

Document Version

Publisher's PDF, also known as Version of record

Link back to DTU Orbit

\section{Citation (APA):}

Mikkelsen, T. (1982). Description of the Risø Puff Diffusion Model. Risø National Laboratory. Risø-M No. 2361

\section{General rights}

Copyright and moral rights for the publications made accessible in the public portal are retained by the authors and/or other copyright owners and it is a condition of accessing publications that users recognise and abide by the legal requirements associated with these rights.

- Users may download and print one copy of any publication from the public portal for the purpose of private study or research.

- You may not further distribute the material or use it for any profit-making activity or commercial gain

- You may freely distribute the URL identifying the publication in the public portal

If you believe that this document breaches copyright please contact us providing details, and we will remove access to the work immediately and investigate your claim. 
RISQ-M-2361

DESCRIPTION OF THE RISO PUFF DIFFUSION MODEL

Torben Mikkelsen

Abstract. The Riso National Laboratory, Roskilde, Denmark, atmospheric puff dispersion nodel is descrited. This three-dimensional model simulates the release of Gaussian pollutant puffs and predicts their concentration as they are diffused and advected downwind by a horizontally homogeneous, time-dependent wind. Atnospheric characteristics such as turbulence intensity, potential temperature gradient, buoyant heat flux and maximum mixing depth have been considered.

INIS descriptors: ADVECTION; AIR POLLUTION; BOUNDARY LAYERS; CLUSTER EMISSION MODEL; COMPUTERIZED SIMULATION; DIFFUSION; EARTH ATMOSPHERE; HEAT FLUX; METEOROLOGY; PLUMES; SPATIAL DISTRIBUTION; TEMPERATURE INVERSIONS; TRAJECTORIES; TURBULENCE; WIND

UDC $551.510 .4: 681.3 .06$

October 1982

Riso National Laboratory, DK 4000 Roskilde, Denmark 
ISBN 87-550-0885-2

ISSN 0418-6435

Risø Repro 1982 
TABLE OP CONTENTS

1. INTRODUCTION

2. RISO PUPF MODEL

2.1 General Characteristics

2.2 wind Field

2.3 Turbulence Intensity and diffusion

2.4 Plume rise ............................

2.5 Reflection

2.6 Limit of mixing depth

3. ACKNONLEDGMENT

4. REPERENCES

\section{APPENDICES}

A. Major sections of the puff model

A. Input data section

B. Initial section

C. Calculation section

D. Output section

E. Error diagnostic section

P. Subroutines

B. Puff model flow chart

C. Puff model contractions

D. Listing of Puff Model computer code 



\section{INTRODUCTION}

The downwind transport and distribution of atmospheric pollutants from a isolated source over land or water has become an important environmental factor in today's society. The need to understand the distribution of smoke, unpleasant or potentially harnful foreign gases and perhaps radioactive debris from a nuclear power plant accident are becoming nore and nore essential for industrial operations and construction planning. The dispersion of such atmosphe:ic pollutants is comonly modeled by a standard Guassian plume model which computes onehour average plume characteristics.

The Meteorology Section of the Riso National Laboratory. Roskilde, Denmark, has recently developed a puff model for prediction and simulation of atmospheric pollutant diffusion.

The model considers individual puffs of pollutants with specific release rates that are advected by a horizontally homogeneous wind over a grid. The wind input may be either the measured wind from a single point, a spatial average or a wind simulation. The model simulates the instantaneous plume characteristics by adding a group of puffs, growing in size, as they advect with the wind. A Gaussian plume model, on the other hand, provides a time averaged concentration pattern based on a single time average wind vector. In the puff model, the plume advects with a time series of actual wind data. Thus, the puff model is able to predict time varying concentration distributions in actual changing wind conditions, making it an appropriate tool for dynamical computations of downwind dispersions of pollutants.

A basic comparison of a puff model simulation and a typical plume is illustrated in Fig. 1. Looking from above, the instantareous behaviour of a plume being advected from a source by the wind is shown. The outer cone-shaped contours represent the outer 1 imit of the plume boundary and are identical in both Pigs. 1 (A) and (B). 


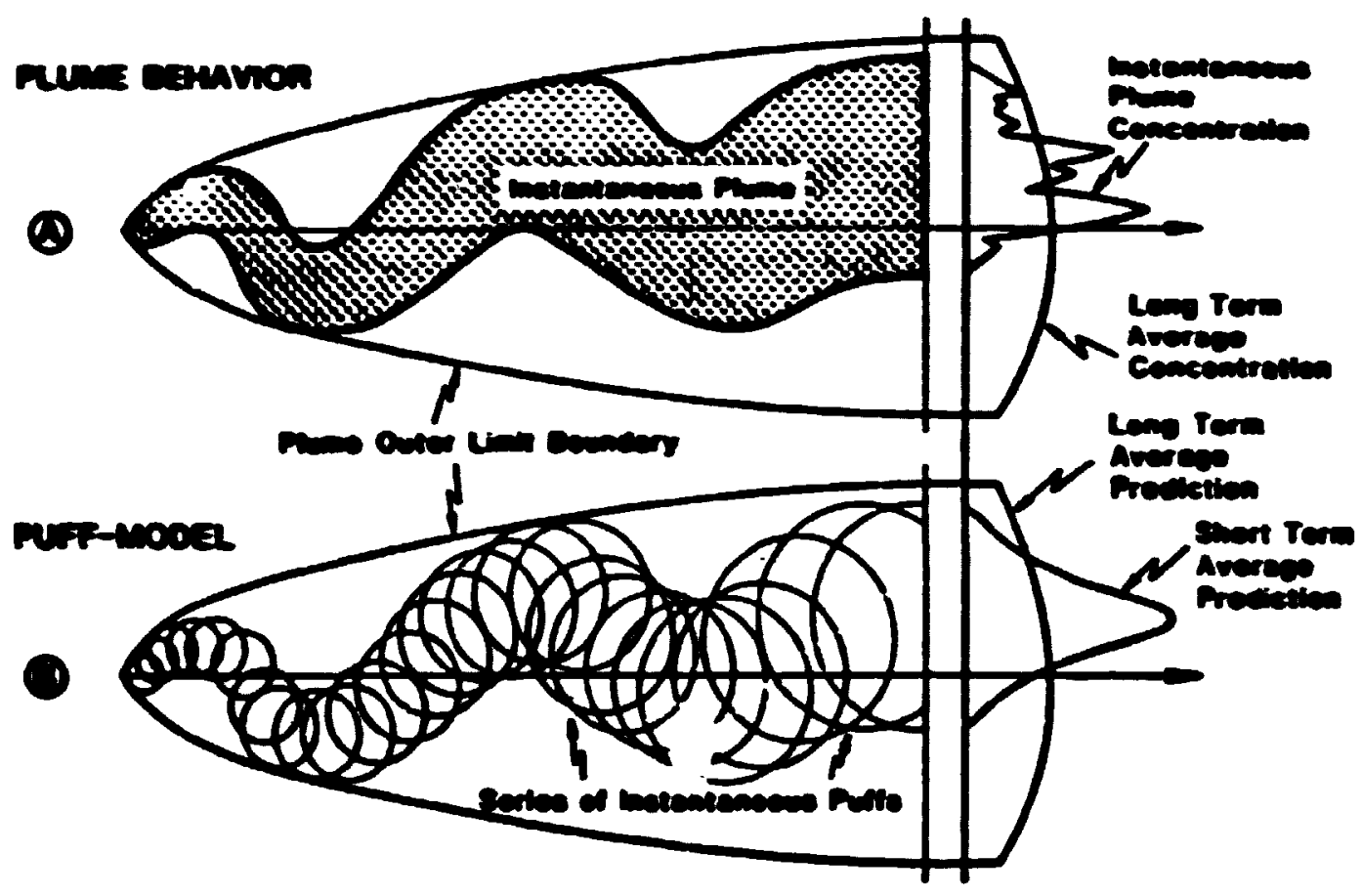

Fig. 1. Instantaneous behaviour of typical plume and a series of puffs from a puff model.

Fig. $I(A)$ shows an instantaneous depiction of an actual plume. The long-ter average plune concentration is show on the extreme right as a swooth curve with a maximum on the central axis. Also shown is the instantaneous plume concentration considered realistic but is of such a short time scale that it cannot be predicted or easily measured.

The puff model prediction is depicted in Fig. 1(B). The circles show the boundaries of individual puffs of pollutants released from the source. These puffs are advected and diffused downwind by a frequently updated wind. The long term average concentration prediction of the puff model is expected to be identical to the long term concentration of Pig. 1(A). The short term average pollutant prediction, a Gaussian curve shown on the extreme right, is not completely realistic but is a reasonable approximation to the instantaneous plume concentration profile. 
2. RISO POFF HODEL

\subsection{General characteristics}

The Rise puff nodel is a three-dimensional computer nodel used for the prediction and/or simulation of the diffusion and advection of atmospheric pollutants. The puff model technique is to simulate a plume with Gaussian shaped puffs with specified release rates within a specified grid. The initial size of the puffs is normally one neter in dianeter although this can be easily adjusted. The anount of material in a puff is the release rate tines the elapsed time between puffs. Therefore, a long elapsed time between puff releases results in a higher initial puff pollutant concentration than a short time interval. This should not normally be of concern if an adequate balance is maintained between grid size, advection speed and puff release

The location of the puffs on the grid is determined by computing their movement for a finite time step using a measured wind field. The growth and buoyancy of the puffs are computed from simultaneous specifications of atmospheric turbulence intensity and stability and from buoyant heat flux at the source. An inversion cap through which pollutants cannot pass and the source height where pollutants are released are variable and can easily be adjusted. Grid distances within the model may vary from meters to kilometers and time durations from seconds to hours are possible.

This puff model has the capability of monitoring a maximum of twenty-five sources of puffs and its grid may contain up to 100 puffs. A puff source can be located anywhere on the grid and have a unique release rate, start and stop of release time, and heat production. When the center of a puff moves outside the boundaries of the grid (either horizontally or vertically), that particular puff is dropped from memory. In this way the model does not store irrelevant puff information, thus keeping computer memory requirements to a minimum. 
A variable to control the amount of reflection/absorption of the pollutant by the surface is easily adjusted in the puff nodel. Such a paranter is of great value both in actual dispersion problens and also for gaining understandings of the plume/surface relationship.

The model calculates the concentration at each grid point by suming the contributions fron surrounding puffs for each advection step. The grid concentrations can be allowed to accunulate or simply be updated with the latest instantaneous value. A mininum grid concentration of interest can be set to reduce computer run time by dropping concentrations too small to be of interest.

The output of the model contains periodic results of puff locations and concentrations as well as initial input verification. The time interval for the periodic results is adjusted by the input data. This recurrent lineprinter output contains:

- $X-Y$ plane plots showing the position of the sources and of puffs inside the grid,

- $x-z$ plane plots of puff positions for evaluating plume rise for each vertical level of interest, and

- a table listing of the grid point concentrations for each level.

A computer drawn contour of the magnitudes of the pollutant concentrations is also available.

When considering distance between gridpoints (delta $X, Y, Z$ ), only spatial resolution and computer resources need be considered, calculated concentrations accuracy is not related to the grid-point separation. To ensure that no essential information on individual puffs is "hidden" between grid points, the grid separation should be adjusted dependent upon the $\mathrm{gize}$ 
of the puffs at the downwind distance of interest. Other specific model configuration considerations are described in the following sections. They are also discussed in more detail in the model behaviour chapter.

\subsection{Wind field}

Once a puff is released, it is advected based upon wind data measurements at a single point only, normally the release point. This limits the validity of the model to situations where the wind field and turbulence can be assumed to be horizontally homogeneous throughout the grid. It is therefore important to ensure that the data obtained from such a single point measurement is representative of the wind structure for the whole area of interest.

The wind data are normally obtained in the form of a horizontal velocity time series. A vector sequence is formed by averaging over a convenient interval. These data are read into the model after being segregated into turbulence classes as discussed in the next section.

\subsection{Turbulence intensity and diffusion}

The growth/diffusion of a puff depends upon the turbulence intensity. To accoaunt for this growth, the puff model applies the theory for relative diffusion suggested by Smith and Hay (1961).

The turbulence intensity is defined to be the standard deviation of the wind direction (in radians) squared. These standard deviation values are collected for the same short time periods as the wind speed measurements used to advect the puffs. Therefore, the intensity of the turbulence which governs the relative diffusion of the puffs, can be adjusted along with the advecting wind speed after each time step, if the stability conditions changes. 
A very low value of turbulence intensity represents a saall standarad deviation. normally a stable atmosphere and a weak puff dispersion/diffusion. As the atmosphere becones wore unstable, the turbulence intensity increases along with an increase of theurind direction standard deviations and plume dispersion/diffusion. While these characteristics are resentative of turbulence over land, they can be applied to over water cases in a broad sense.

\subsection{Plume rise}

In the vertical direction, puff-rise can be accounted for by Briggs (1970) plume rise theory. In this case buoyancy is assumed to be conserved (adiabatic motion), and pressure forces, molecular viscosity and local density changes are considered small and are neglected. The rate at which a puff rises as it is advected downwind is a function of the buoyancy flux, wind speed, puff distance travelled and stability of the atmosphere. Plume rise is considered separately for each indvidual puff.

\subsection{Reflection}

The interaction of the pollutant with the surface is adjustable and can be easily changed in the il.put data. Total reflection or absorption or a fraction between the two can be used.

\subsection{Limit of mixing depth}

The effect of an atmospheric lid (inversion) can be applied in the model to limit the vertical movement of the pollutant. The model does not permit the plume to rise above this cap. When a mixing level is in effect, it acts to totally reflec the pollutant in the same manner as total reflection at the surfave. This mixing cap also acts as an inversion 1 imiting the vertical diffusion of a non-buoyant puff. 


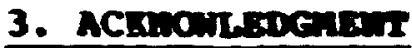

Stephan $\mathrm{K}$. Rinard, The Waval Rostgraduate School, Monterey. California is grateful ackonledged for, in conaection with his enster thesis: - An analysis of a puff dispersion nodel for a coastal region". to significantly inprove the previous description of the niso puff nodel (niklkelsen, T. (1979) Simlation of obscuration snoke diffusion, 73 PP).

\section{Repersuces}

nikkelsen, T. (1979). Simulation of obscuration soke diffusion. Work done under contract to the Danish Defence Research Bstablishment/Rise. 73 Pp. Available from: netcorology Section, Physice Department, Rise uational Laboratory. Dx-4000 Boskilde. Denark.

Rinard. S.K. (1982). An analysis of a puff dispersion nodel for a coastal region. naster's Thesis from maval postgraduate School, Monterey, California, 80 pp. 
APPENDIX A

Major Sections of the puff model

The Rise puff model code has previously been described Mikkelsen, T. (1979). The code also is well documented with comment statements. With that information and the outline to be provided in this and the following appendices, the computational and input/output procedures will be obvious.

The program and input data are stored on cards for the sake of permanency. For effisient operational execution, the program and input data cards are read on a disk within the computer. The model can then be run at will without reference to the original data cards. Minor changes can easeily be made directly on the disk both to the model and/or data before each execution.

The model can be separated into the following main sections:
a) Input data
b) Initial
c) Calculating
d) Output
e) Error diagnostics
f) Subroutines

These will be described separately in the following sections. 


\section{A. Input data section}

The input data includes the variables shown in Table IV.

\section{Table IV}

Input Data Variables for the Puff Dispersion Model

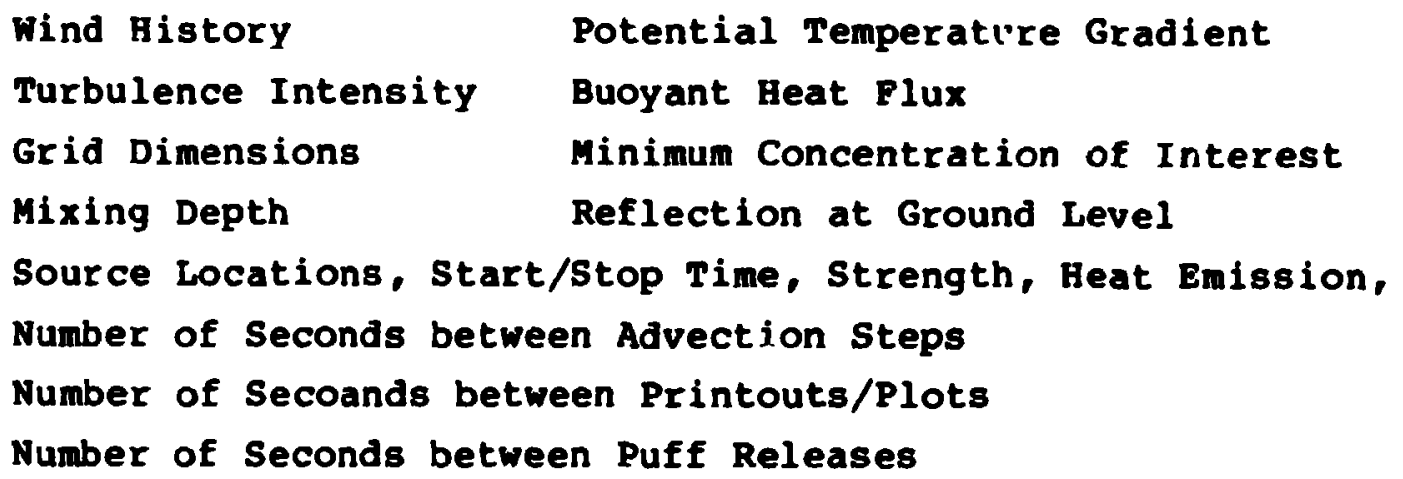

The wind field and stability class for the current time step are read at the start of the calculation section.

The variables listed above are printed as input data check and a permanent record to accompany the actual output. In most cases the print comnand can be overridden by YES/NO options.

\section{B. Initial section}

Based upon the input data from section (A), the initial section specifies and initializes parameters to bs used in the calculating section and is passed only once during execution of the model. The grid and some counters are initialized. Constants relating to reflectance, $\mathrm{mixing}$ depth and stability as well as those controlling the size of some of the loops within the model are established. Parameters such as number of puff releases per second, number of advection steps per second and number of advectionb steps per puff release are determined. 


\section{Calculation section}

Using current wind and stability class data read at the start of the calculation section, the model advects the puff centers and calculates the growth rate and plume rise of the puffs. It removes the puffs that have left the grid (horizontally and/or vertically). The predicted concentration is computed at the grid points to include pollutants from all nearby puffs.

\section{Ontput section}

Por time intervals designated by the input data, printer plots of the $X-Y$ and $Y-Z$ grid are produced. A maximum mixing level is marked on the $Y-Z$ grid if in effect.

These plots include the source location and a trace of the plume from the release time $t$ the maptime. Also printed at this interval is a $X-Y$ table of grid concentrations for each vertical level of interest. These concentrations can be either accumulated or actual concentrations at the plot time.

Added to the puff model is a versatic plotter routine to smooth and contour the grid magnitude concentrations of the above tables.

\section{E. Error Diagnostic section}

If the model is directed by the input data beyond the limits of the design of the program, the program is terminated by way of the ereror diagnostic section. It prints comments relating to the commonly made input errors enabling the user to isolate problems. 


\section{F. Subroutines}

The subroutine "sigris" calculates the puff size in the horizontal and vertical directions. It also estimates plume rise associated with pollutant buoyancy.

The subroutines "I space" and "Rspace" are used in the framework of the printer plots.

The subroutine "Plout" converts the plume concentrations to a logarithmic values, smoothes and then contours them using Riso inhouse contour subroutines. The values are converted to their logarithm values so that the problem of contouring over many orders of magnitude is simplified.2A 
APPENDIX B

PUFF MODEL FLON CHART

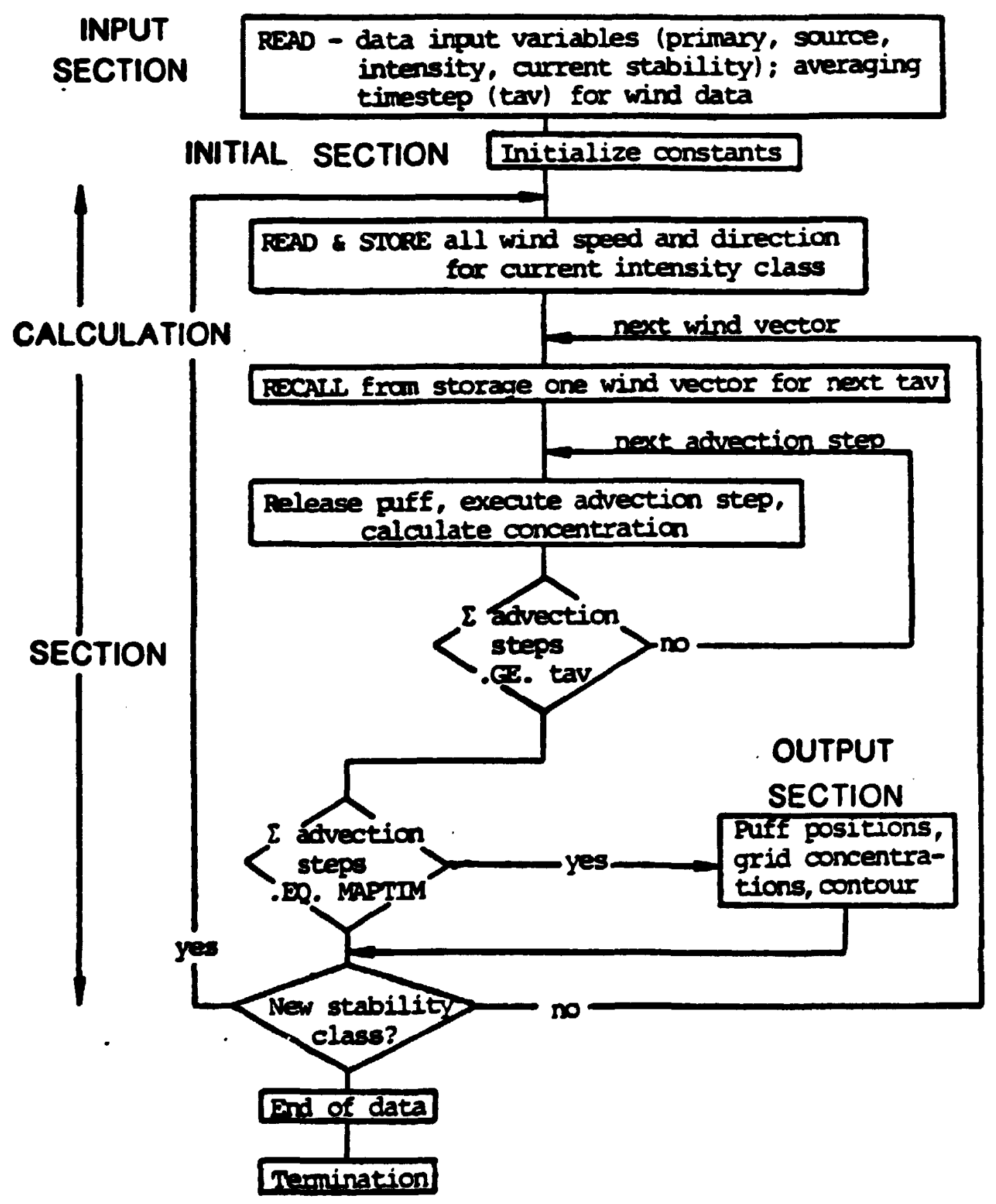


APPENDIX C

Puff Model Concentrations

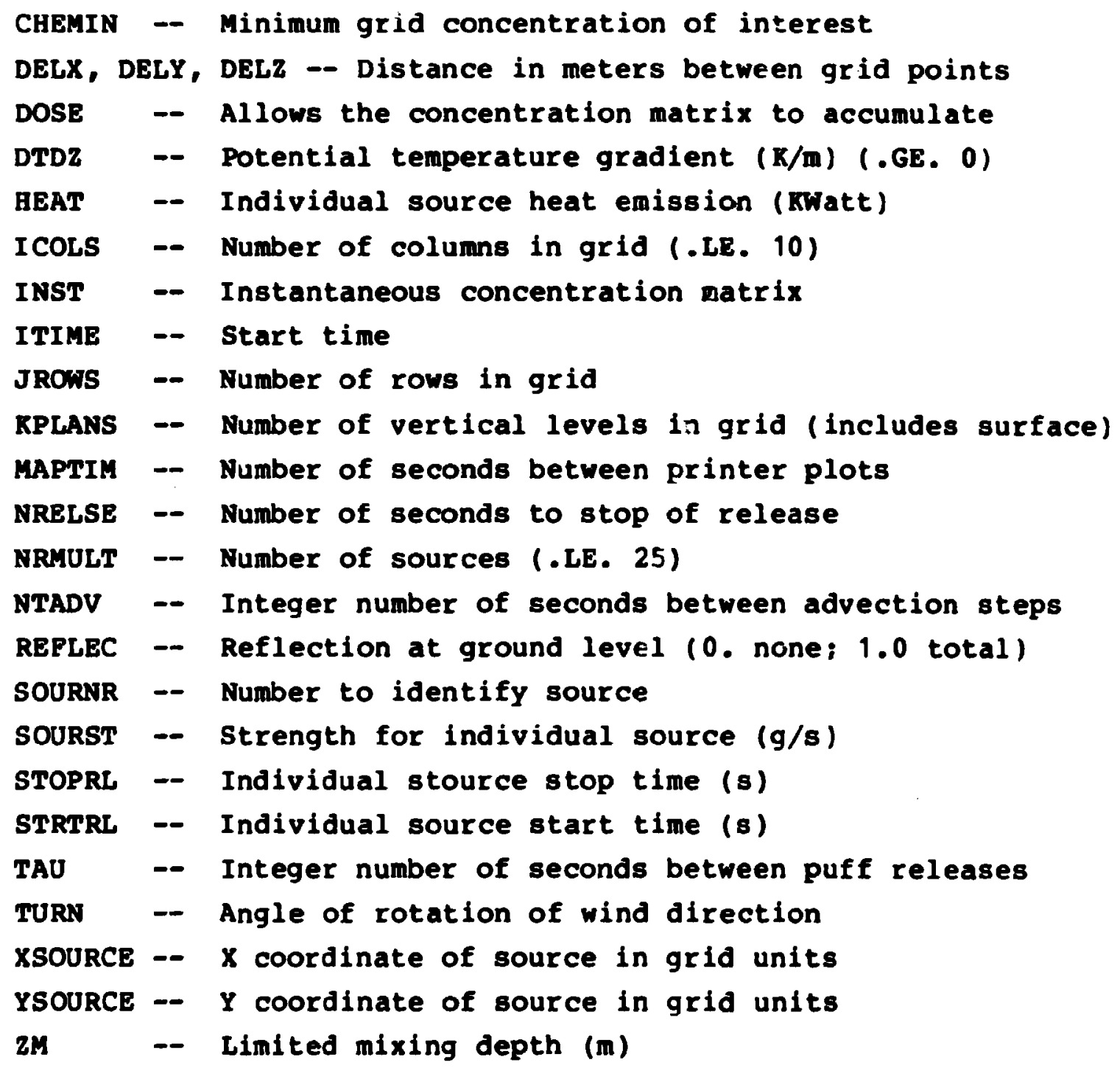


I' EXEC PGM EIEBGENER

A PPEWDIX D

COSYSTH o douny

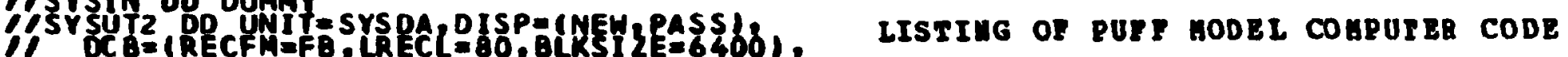

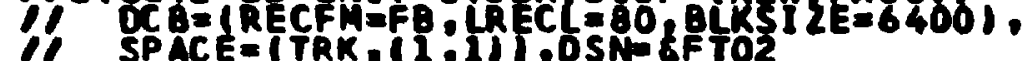

isysuT1 od

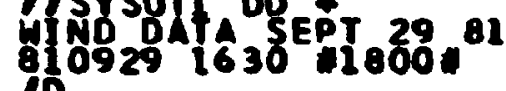

$085 * 04.70085 * 04.8$

6 EXEC FRTXCLEN BNAME=CONRECOC

IFORT SYSPR INF DO DURMY

$c$
$c$
$c$
$c$
$c$
$c$
$c$
$c$
$c$
$c$
$\varnothing$
$c$
$c$
$c$
$c$
$c$
$c$

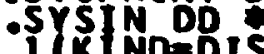

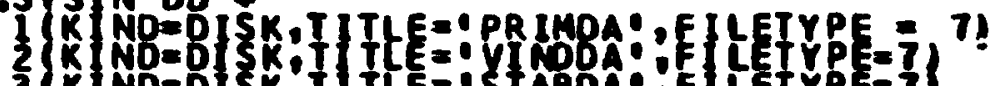

3 KIND=DISK:T TLE= STABDA OFILETYPE=7\}

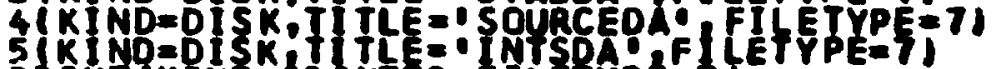

PRINTIKINOSPR ANTER,FILEPYPEE T

GIKI ND= PRI NTER, FILETYPE= T)

THIS MICRODIFFUSLOM PROGRAM REPRESENTS THE STATE-OF-

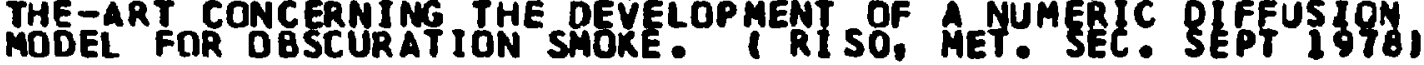

THE PROGRAM IS DOCUMENTED BY HEAVY USE OF COMMENT STATEMENTS. FOR COLLECTING AN OVERAL YIEE DE THE PROGRAM STRUCTURE, AS COENSULT THE FLOWCHARTS AND DESCRIP TIONS IN THE CONSECUTIVE REPORT.

COMMON HEATFX(25), 2 , DAS, POINT, INTENS( 14), STABPA, F BUFLX

1 SPEED GONSTI DEL

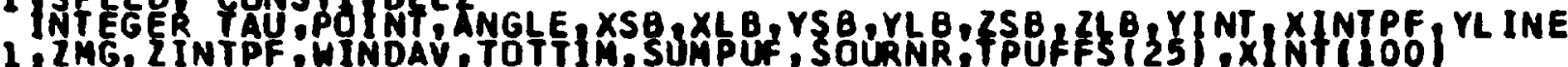
INTEG XR XSOURC (25): YSOURC 25 i, STRTRL(25), STOPRL (25)

puF 89818

PU $=80030$

PuF 00040

ouf 88868

PUF 9078

PUE 00168

putgoito

PuForigo

Pugos

Ut80210
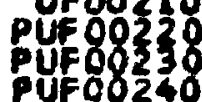

Put 00250

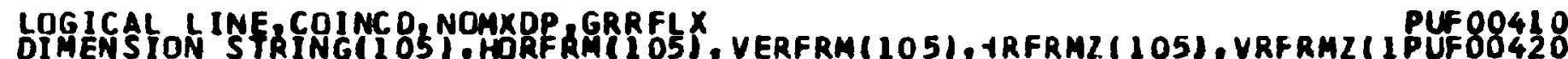

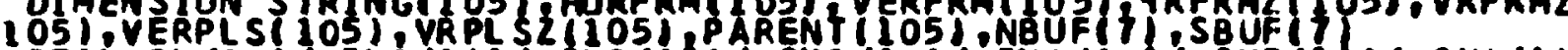

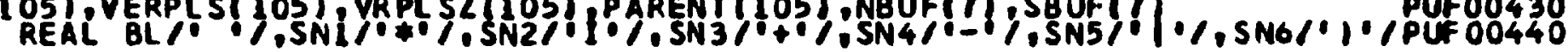


DIMENSION TITLE(18), HINOTX(18) PUFFTX 12 O INTSTX(10) STABTX(18)

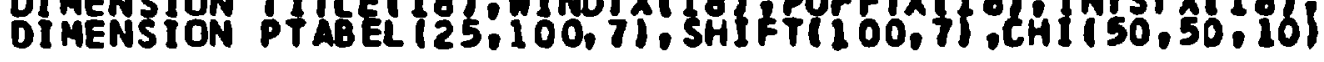

PUF 90450

DIMENSION ABC(10), SOURST (25), CPLOT (10,17), SOHT (25)

PUF 00480

REAL DATA114), TYPE (14), INTENS

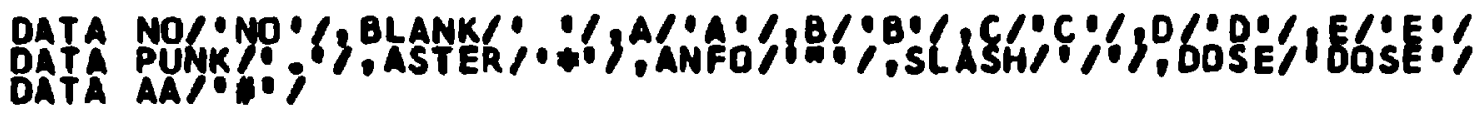

PUF 00500

ह

PUF 00549

PuF 0055

SuF 89598

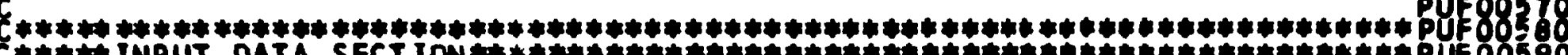

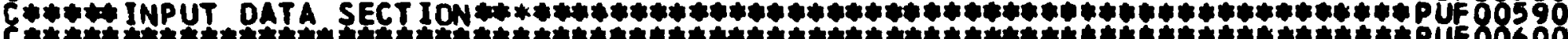

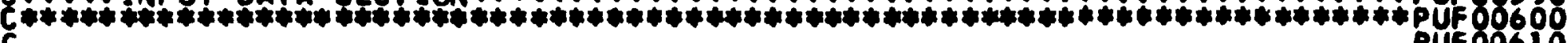

¿ INPIT DATA FROM DATA FILE PRIMDATAs PRIMARY DATA FOR PUFF MODEL

C READ PRIMDA , CARD NO 18

CI READI H IO G ITIME,NRELSE ONSTEPS, ICOLS, JROUS , KP. ANS , NTADV

C READIZZO) MAPTIM.TAU TURN

C REAOIISO

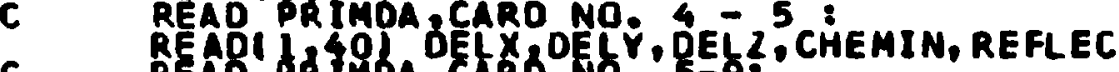

C RADR

C END OF PRIMOA - INPÛ́ FILE.

buF 886318

PUF 00640

PuF 00650

PU: 8068

PuF 068

PUF 00698

PuFoo700

PuF 90738

Pu= 8073

PUE 8748

Pue 70

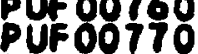

pufo8788

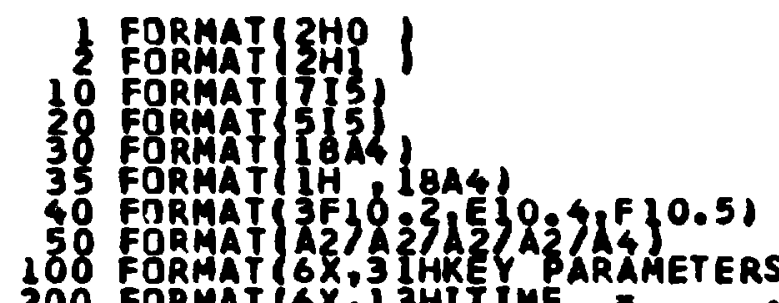

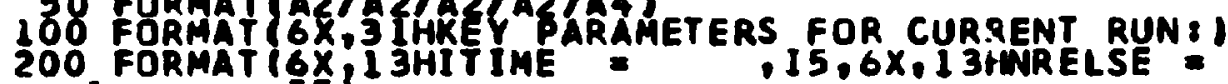
300 FORMAT $16 x_{1}, 13$ HICOLS $=.15 .6 X_{0} 13$ HJROWS = 400 FORMATI $6 \mathrm{I}^{1}, 13$ HNTAOV $=.15,6 \mathrm{X}, 13$ HMAPTIM $=$ $, 15,6 x_{1} 13$ HNSTEPS $.15,6 x, 13$ HKPLANS , 15,6X.13HTAU

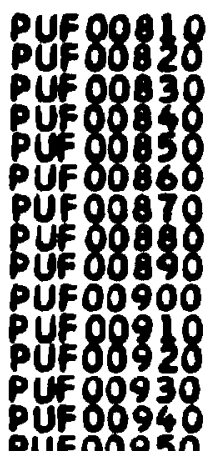
$1=$

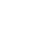




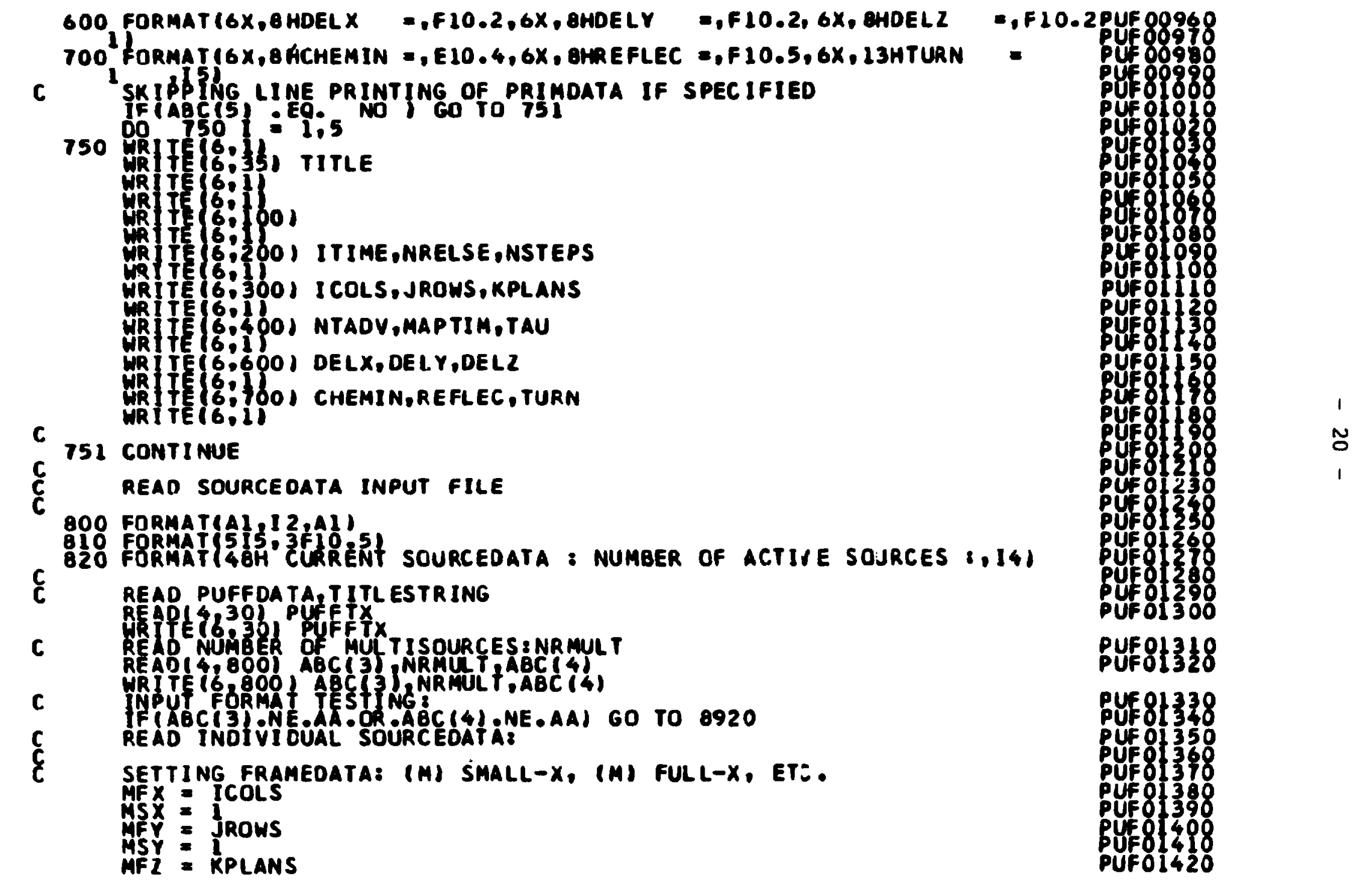




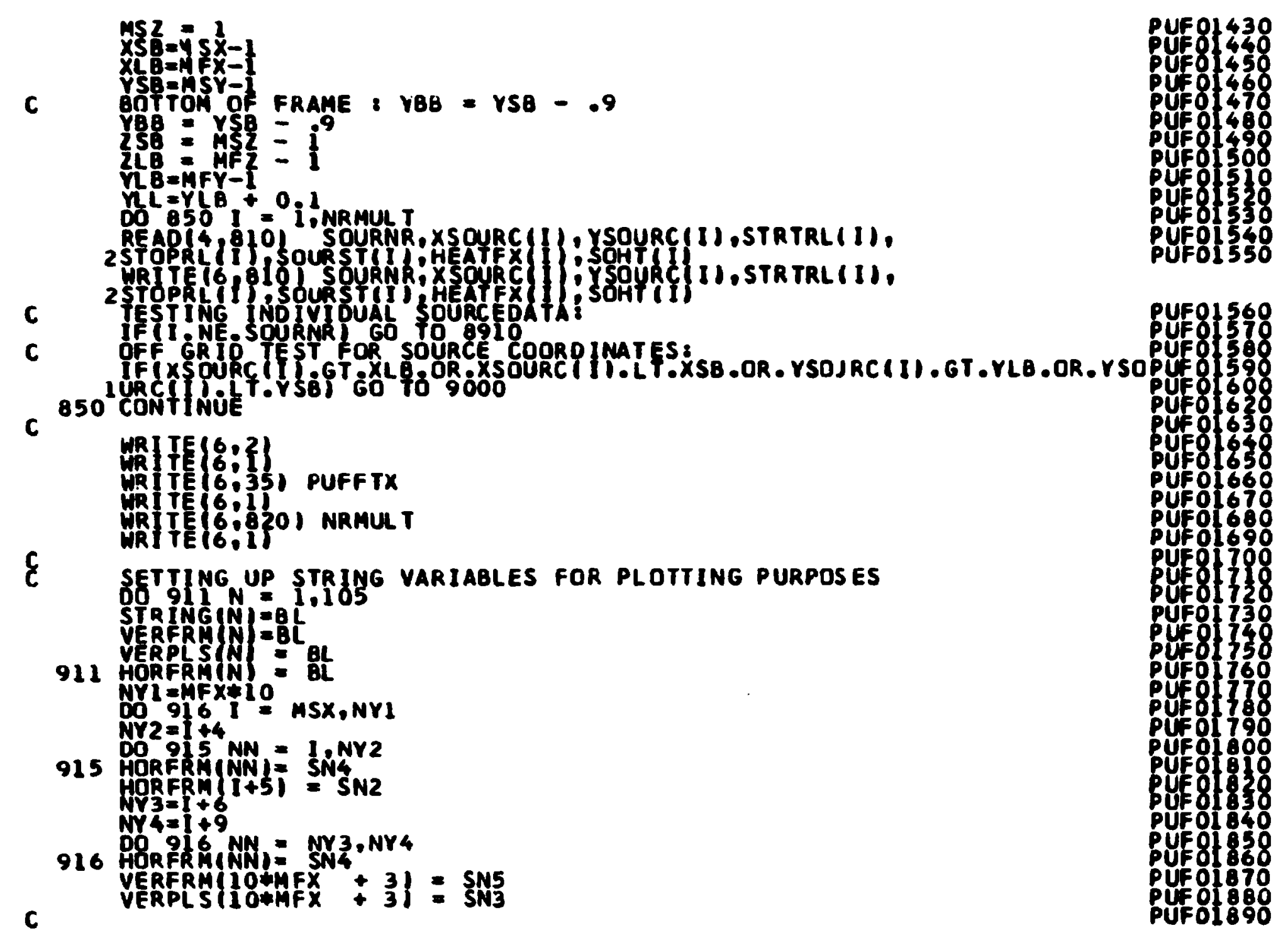


C OUTPRINTING CURRENT SOURCE POSITIONISI IN GRID PICTURE

C SKIP PLOT OF SOURCE, POSITIONS IF SPECIFIEO IN JRIMOA

C

860 IF'ICOLS .6T 101 GO TO 995 SOURCE DATA AS SPECIFIED,150X,27H IN SOPU:

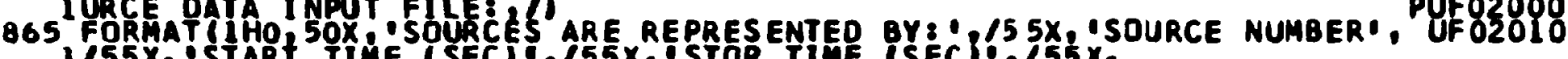

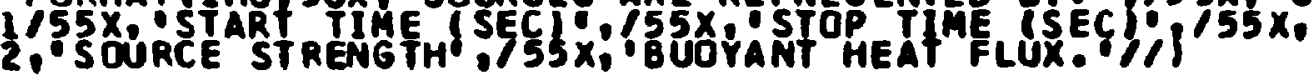

O70 FORMATI2HO 16 H $Y$ COOROINATE OF,25X $32 \mathrm{H} \times$ COORDINATE OF THE GRID PPUF 02050

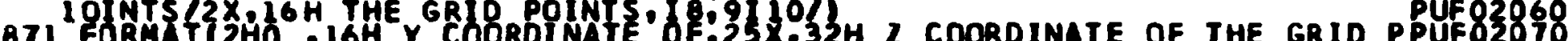

C

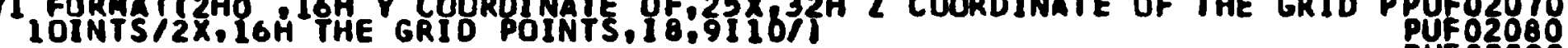

HRITE $(6,860)$

c

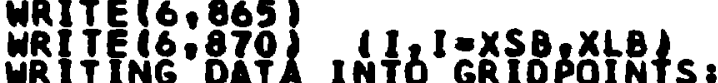

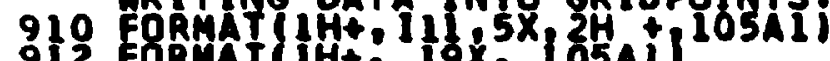

912 EORMAY

C

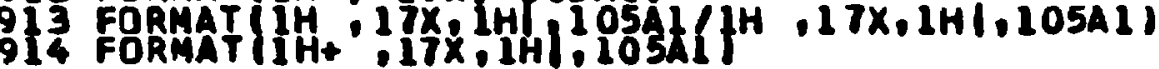

WR IF $\left\{\begin{array}{l}6: 1 \\ 6: 912\end{array}\right)$ HORFRM

NY $5=M A X+1$

Do 950

$1=N Y_{6}-1$

NYG $=1$, NY 5

MAXNI $=$ MAX -

WRITE 16,910 I MAXM1, VERPLS

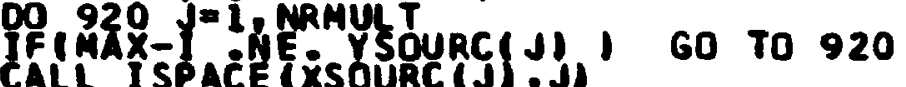

920 CONTINUE

c
WRITE 6.913$)$ VERFRM, VERFRM

DO 932 J = I.NRMULT

IF MAX-I ONE OYSOURC(J) GO TO 932

932

CALL SBACE XSOURC (J),STRTRL (J)

WRITE $(6.9131$ VERFRM, VERFRM

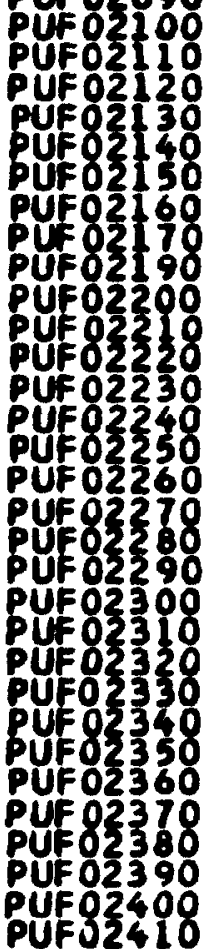


C

DO 934 - J = ME:MRMULT

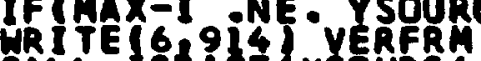
934 CALL HSPAE (XSOCRC (J),STOPRLIJI)

c WRI TE 6,9131 VERFRM, VERFRM

PO $940-1=1$ MRMULT CALE SSPACE IXSOURC (J), SOURST(J))

940 CONTINUE

c WRTE 6,913$)$ VERFRM, VERFRM

OO $930 \mathrm{~J}=1$, MRMULT IF(mAX-1.NE. YSOURC(J) I GO TO 930 CALL RSBGACE (XSOURC(J), HEATFX( J)

930 CONIINUE WRITE 60.913$\}$ VERFRM, VERFRM

C

950 CONIINUE

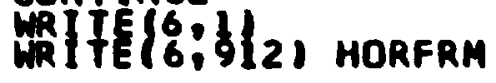

C

990 GO TOO 999 SOURCE DATA PLOT SUPPRESSED BECAUSENICOLSNEXCEEDS 101 995 YRITE 16 (690)

C PEFINE STAB ILLTY AND INTENSITYY CLASSES

960 FORMATU14 F5.41 $70^{2}$ CONNECTED TO INTENSIYY OAFN ASUNDLIHE STI

$\varepsilon$ READ INTSDA TITLE-STRING:

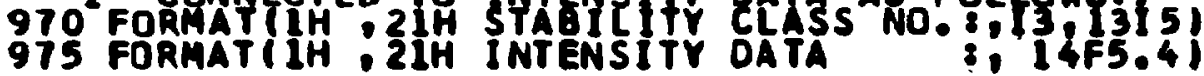

\& READTSBOA INTSTX

$\varepsilon$ RE

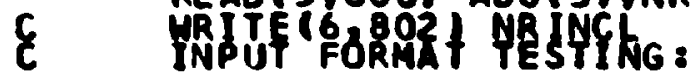




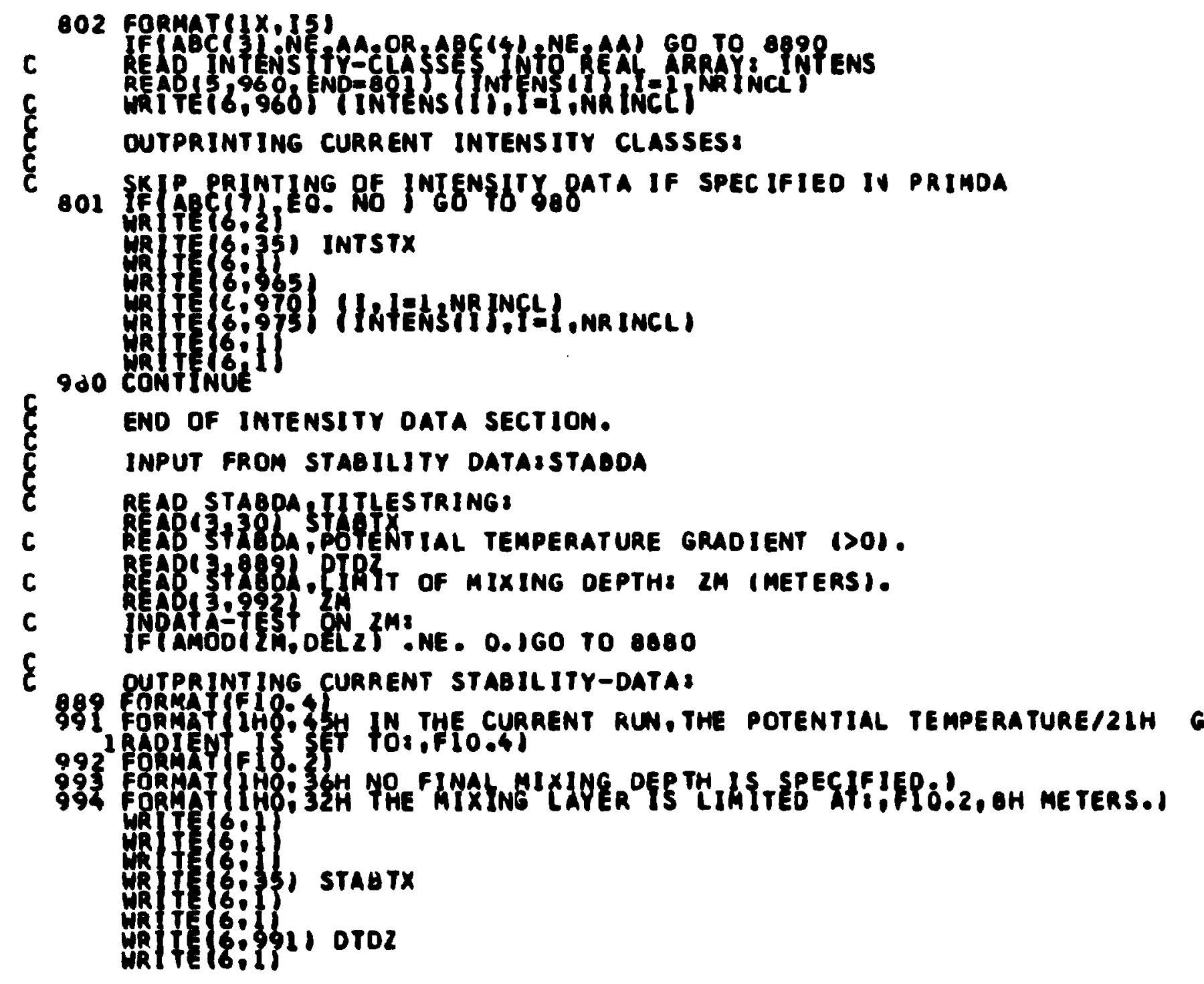

PuF 02900

PuFo3910

PUF02930

Puf 83938

PUE 82978

CUE 0298

PuF 83018
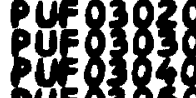

PUF $=3030$

$80=8378$

PUF 0310

PUf03220

PUF 03140

PUFo3 


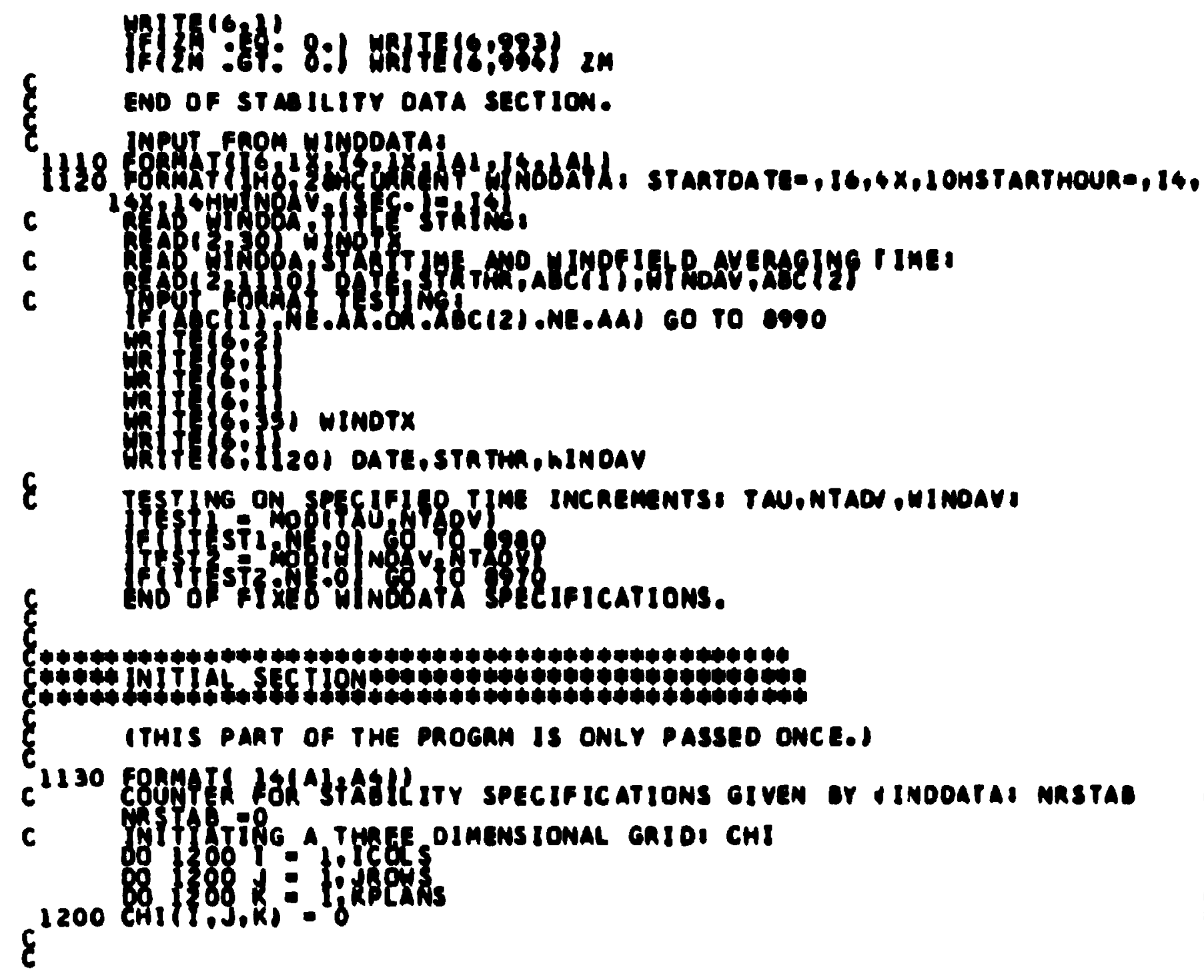




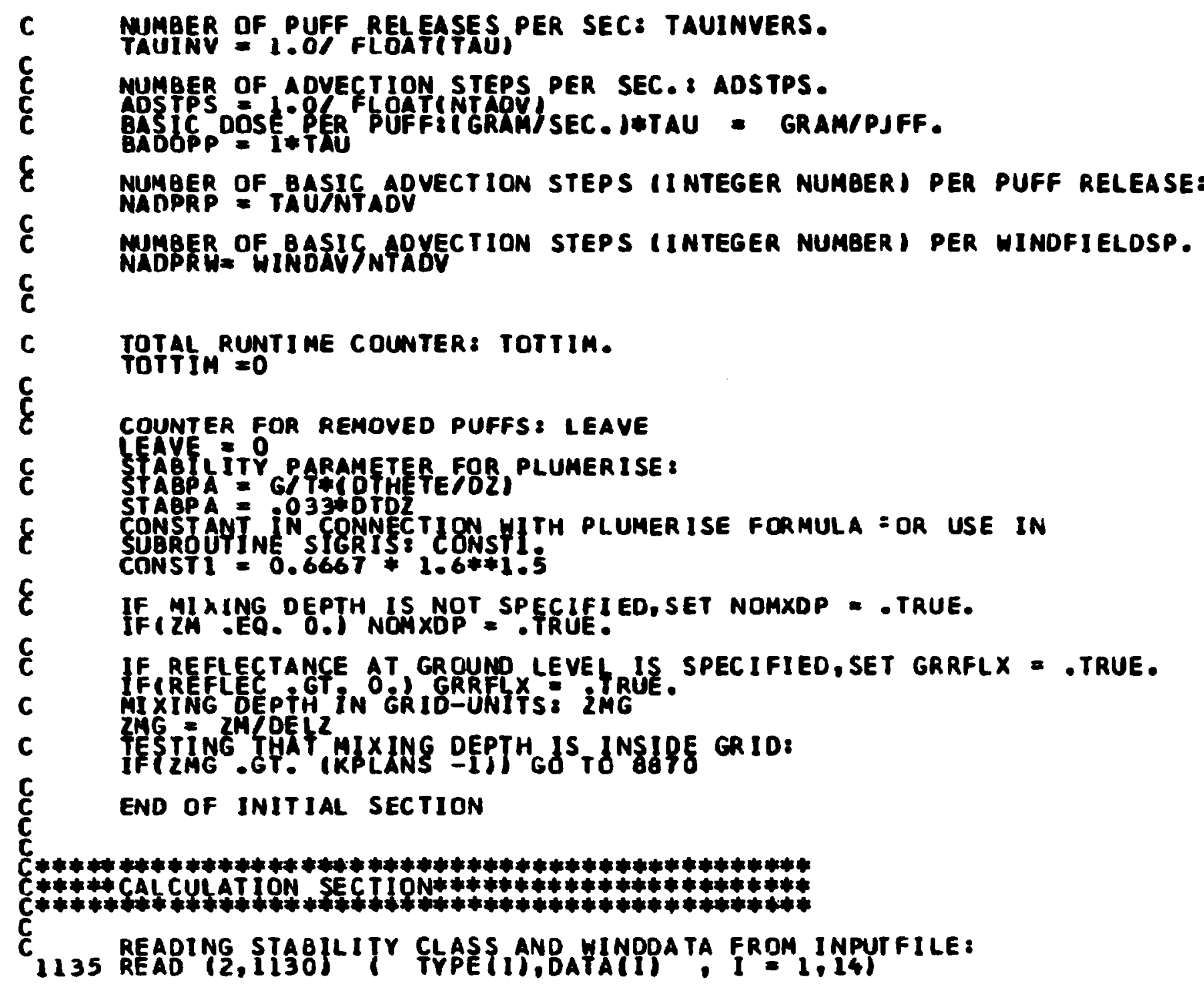

PUF 03860 puf 83 Puf 040 PUF 04010 PUF 04020 Puf 04030 Tu PuF 84860 Puf 4070 U 04080 Uu=8 100 bu= 84138 PUF 04130 PUF 04140 PUF04160 PUF04190 PUF 42218 PUE 8233 PUE 42340 UF $0+268$ PUF 04270 UF 04280 PuF 8300 UF 04310 PUfF 04330 


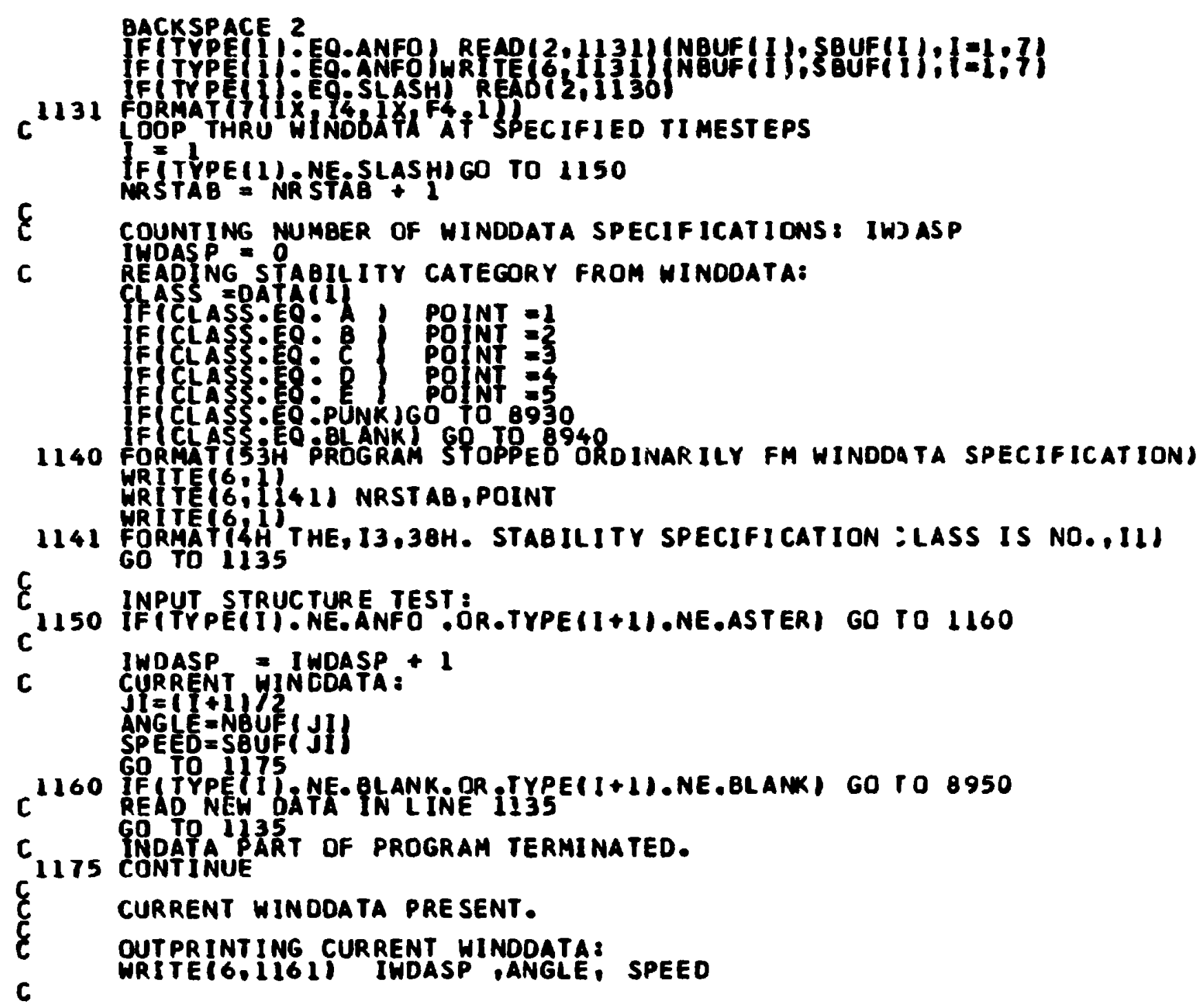


\& CALCULTING HJNO YELOCITY INGRJP UNJTSE YGX,VGY

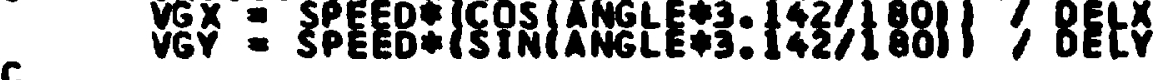

\& Remaning hind aVeraging time a Hindar as tavz

161 L

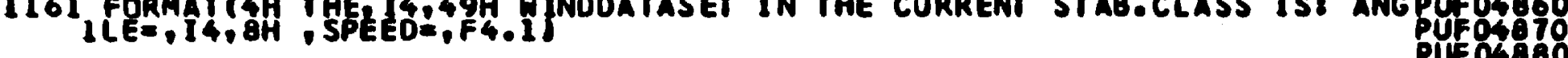

\& LOOP THRU BASIC AOVECTION STEPS WITH CURRENT HINO FIELD PUF 84908

DO 5000 NN=I,NADPRH PUF OS920

C AUMPING OYER MZERO-SETIINGN OF CONCENTRATION MATRIX \& CHI , IF MDOSE MODE IS SPECIF IEO IN PR IMDA.

C

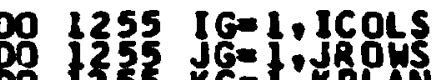

Do $\{255$ KG= TRKPLNS

$1255 \mathrm{CHIIIG,JG,KEI}=0.0$

C 1256 CONTINUE

¿ IIMECOUNTER:TOTTIM ISEC.I

C SRTPPHG RELEASE-SECTIONIF SPEGIFIED

C IESTIMG IF RELEASE CONDOITIONS ARE FULFILLED

C LOOP THRU MULTIPLE SOURCES

¿ INDIVIDUAL RELEASE CONTROL AS SPECIfIED IN SOUZCE daTA:

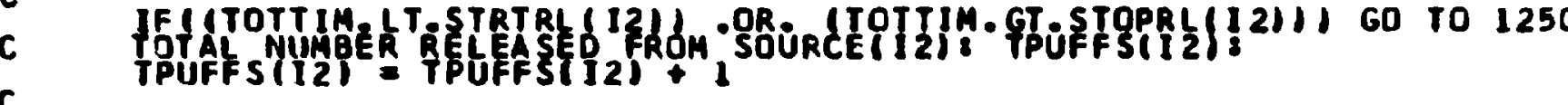

\& SHIFTING PUFF TABLE ONE POSIII ON TO THE RIGHT IND THEREBY

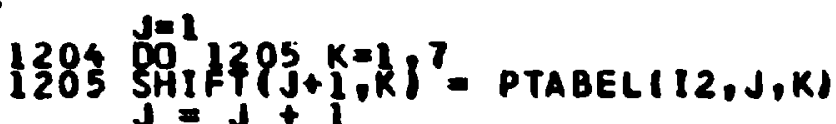

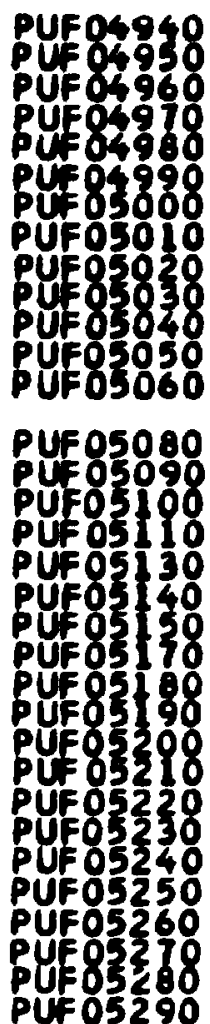




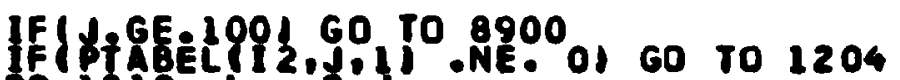

D $1210 \mathrm{~L}=2,3$

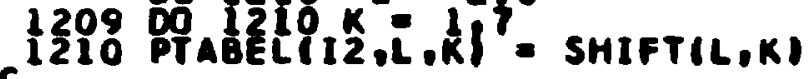

$\varepsilon$ INSERTING NEY PUFF DATA IN PUFF TABLE AT $J=1$

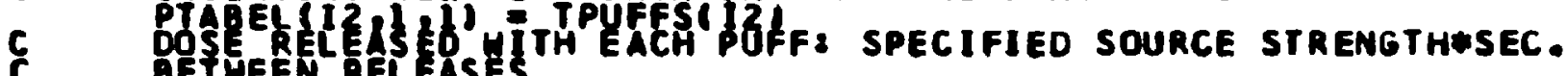

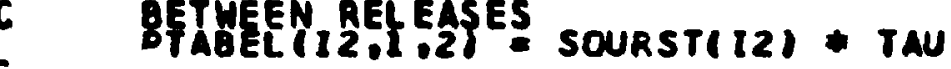

\& DOADING IN INITIAL SOURCE POSITIONS

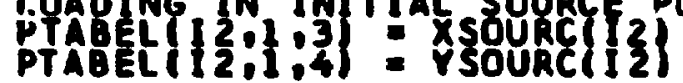

C TO aVOIO NUMERICAL PROBLEMS IN EST IMATING PLUME QISE,

C TET SOHTI 13) SOYRCE HETGHT .GE. I METER.

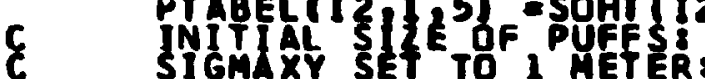

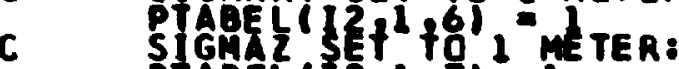

c PHADEL IIDAF PIIELEASE SECTION.

1250 CONTINUE

c aDVECTION OF ALL PUFF CENTERS

C ADVANCE OF PLFF CENTERS IN GRID UNITS (HORIZONTALLY)

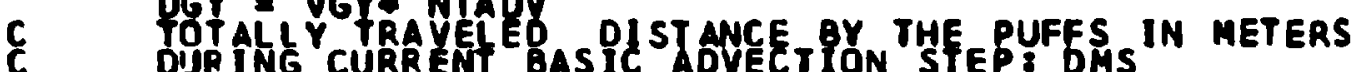

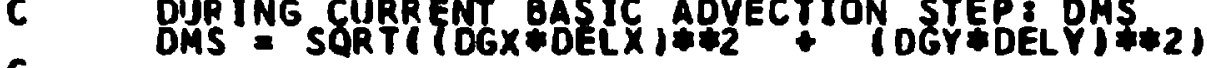

\& ADVECTION SECTION FOR ALL EXISTING PUEFS:

C LOOP THRU AEC SOURCES, COLUNFING REMOVEb PUfF SILEAVE

SKIPPING SOURCE 12 IF THE LAST BORN PUFF HAS LEFT GRID

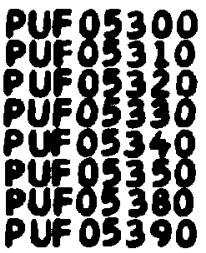

PUF 95410

UY $=85330$

PuF
puts.8358

PUF 05660

1260 IF P PABELLII,

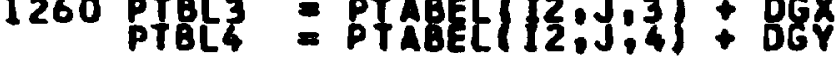

\& CALLING SUBROUTINE NSIGRISN THEREBY ADOING DEVIATION INCREMENT

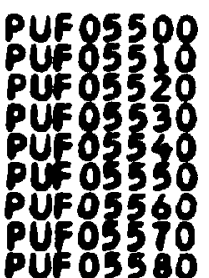

PUF 05630

PUf05650

PUF 05680

Uf 85990

Pye 5738

PUF 03738

PUF 853730

PUF 05770

PUE 85780

Put5790

PUE 55848

PUF 05860 


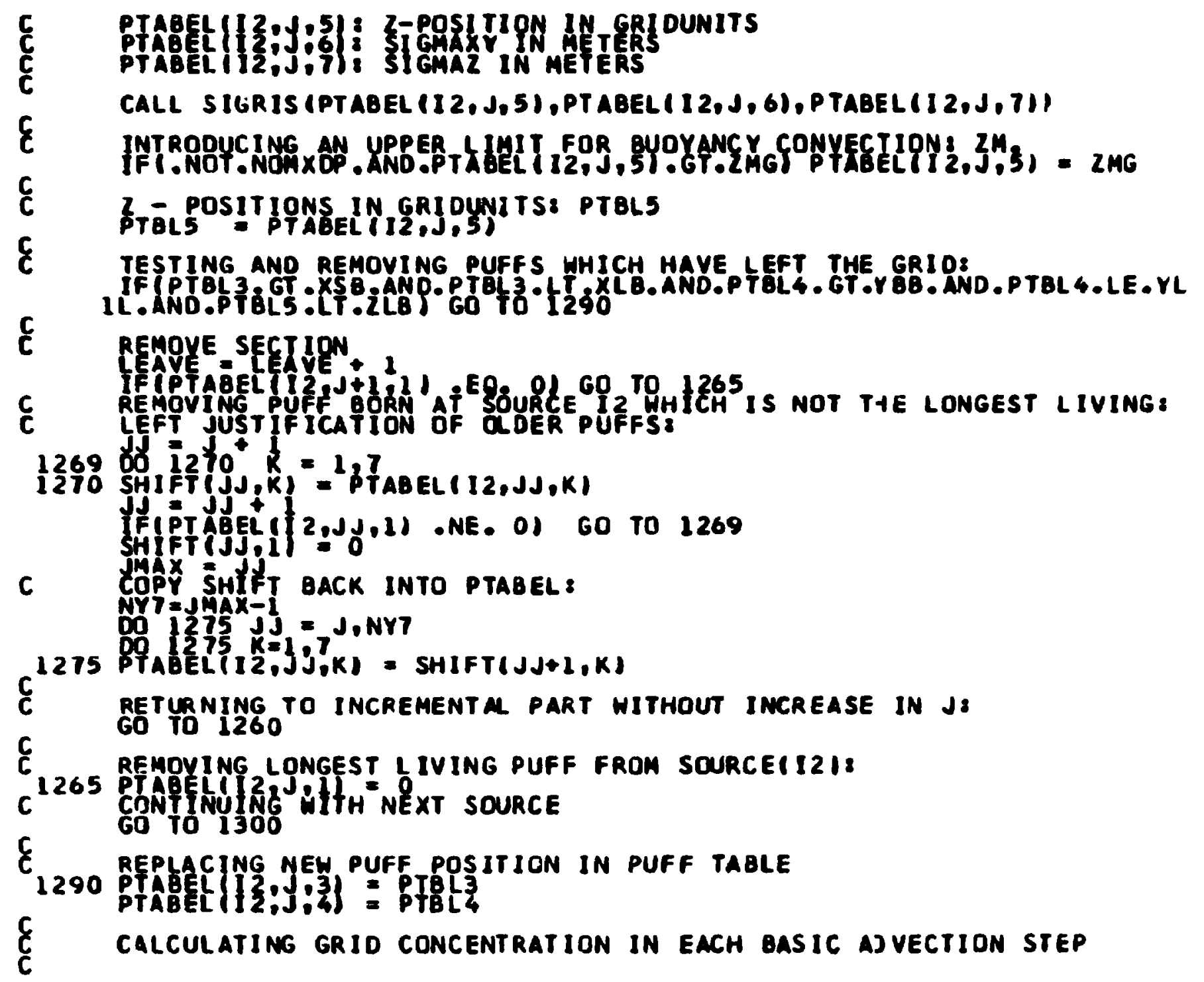

PUF 06200 PuFfo 318 PUF 06230 PUF 8635 PLE 06260 PUF 6378 PuF 06290 WUF 06300 
C RENAMING ESSENTIAL PARAMETERS:

OI $=$ PTAGEL I $2, t_{2}$,

C SIGMA VALUES IN METERS

SIGAZY = PTABEL $\{12 ; j ; 6\}$

C CALCULATING MAXIMUA COMCENTRATION INEACH PUFF CENTER

C COUF

CONST $=15.7496$

PCHCEN = QI/CCONST*SIGHZ\#SIGMXY*\#2I

\& SKIPPING SUMMTION SECTION IF CONCENTRATION IS TOO LOW

C CALCULATING MAXIMUM RADIUS OF INTEREST FOR EACT PUFF:

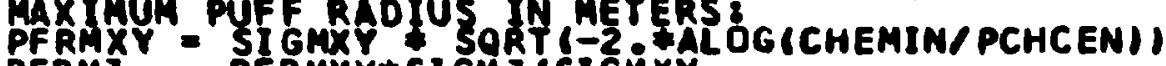
PFRMZ = PFRMXY*SIGMZISIGAXY

\& X-DIRECTION:

C PUFRGX PFRMXY IOELX

C PUFRG

C ZODIRECTION:

¿ OETERMINING START AND STOP GRID POINTS FOR ACCUMULATION OF

C

ISTRTX = PTBL3 - PUFRGX + 1

ISTOPX = PTBL3 + PUFRGX

ISTOPY = PIBLt - PUFRG

ISTRTZ = PTRLS - PUFRG\} + 1

C CONTROL FOR EXCEEDING GRIO DIMENSIONS

IF (ISTRTX.LT.XSB) ISTRTXEXSB

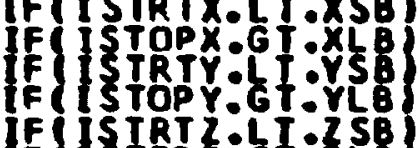

C

STIRTY=X

ISTOPY $=Y L \mathrm{~L}$

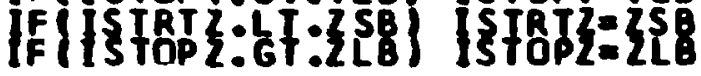

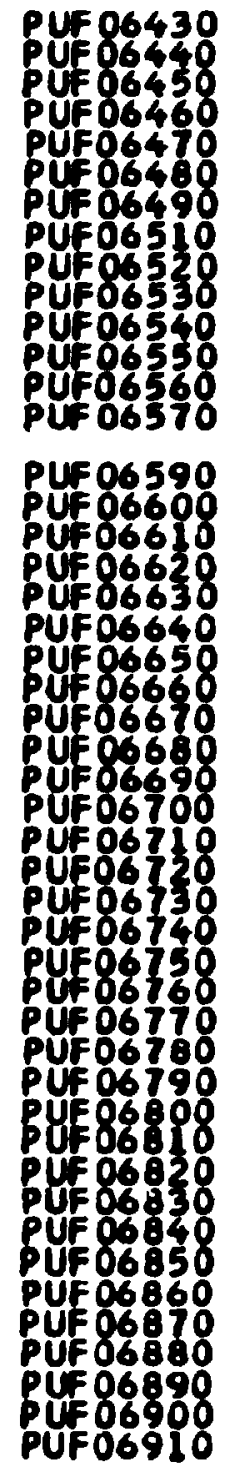


C UPPER LIMIT IN CASE OF SPECIFIED MIXING DEPTHIZM

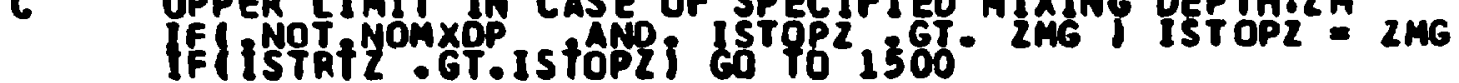

C Cal CUL ATE CONTR IBUTIONS To SURROUNOING GRIDPOINTS

C PRELIHINAR CALCULATIONS:

C SIGGX = SIGRXYODELX SIGGY : SIGMXY'Detr

C CALCULATING DENOMINATOR UNDER EXP-SIGN:

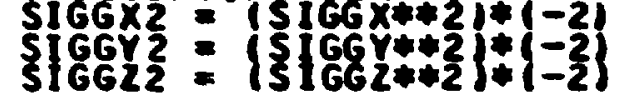

C LOOPING THRU ALL GRIDPOINTS OF INTEREST:

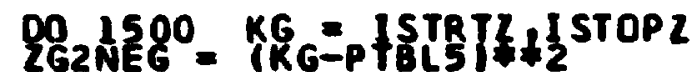

IF (GRRFIX) PCHI = PCHII + PCHCENZFEFLEC*EXP(1 (NomxDP) GO to 1295

作

1295

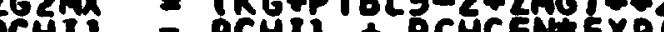

1500 IG = ISTRTX.ISTÓPX

$262 M \times / 516 G 221$

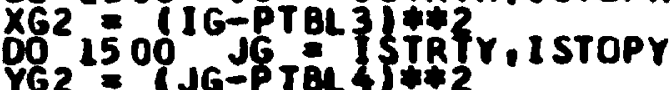

C INOIVIOUAL PUFFS CONTRIBUTION : PCHI,GRAMIM**3

C PCHI = PCHIL * EXP(XG2/SIGGX2 * YG2/SIGGYZ)

C IFEPCI PLT CHEAING GO TO 1500

C CHIIG+1,JG+1,KG+1\}=CHIIIG+1,JG+1,KG+1)+PC+1

C 1500 CONTINUE

C ENO OF CONCENTRATION Calculations

\& aOVANCE in PUfF table (J) DURING BASIC aDVECTIJN Step $J=j+i$

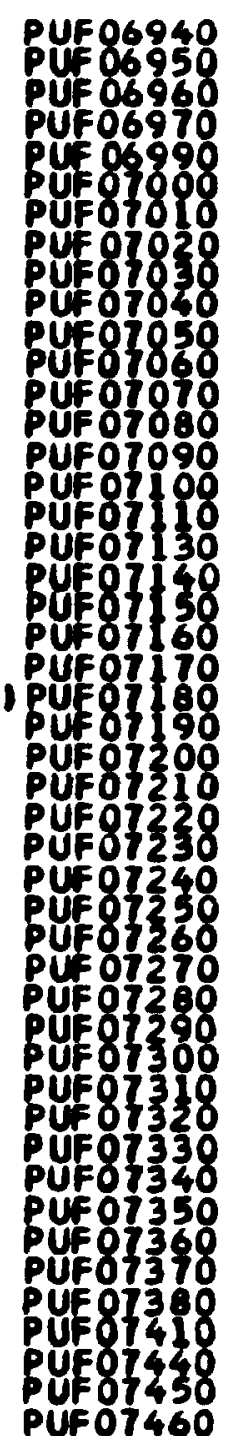




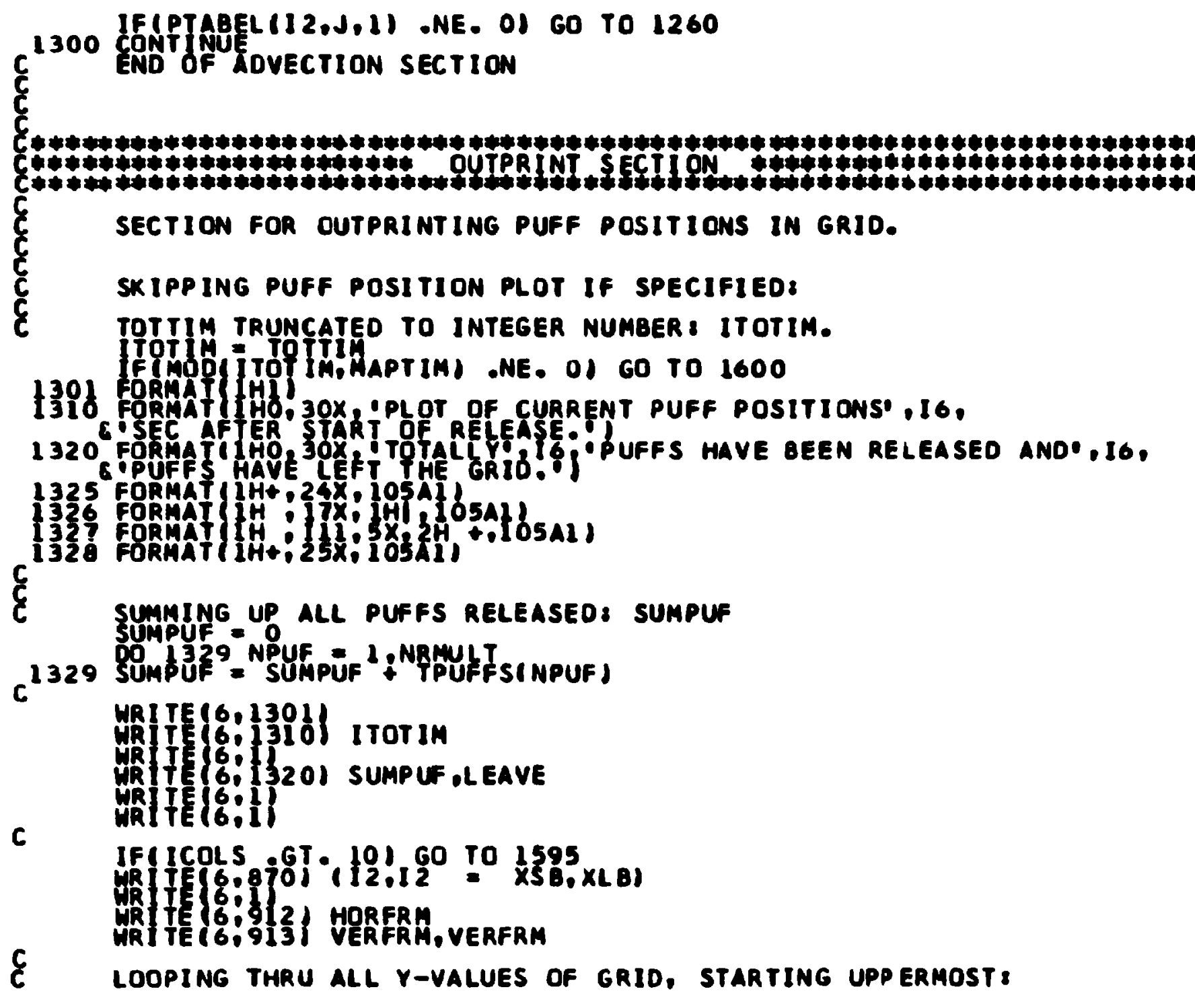

PUF 87478

PUF 07480

UI=879

uty 350

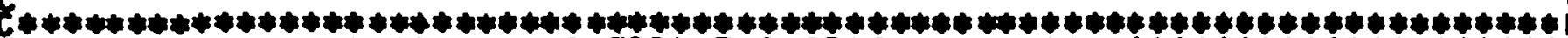

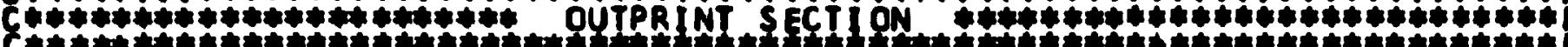

PUE 07610

PuF 87628

PuE 07630

Puf 87658

1310 FOAHAT IHO, 30X, PLOT OF CURRENT PUFF POSITIONS' . 16.

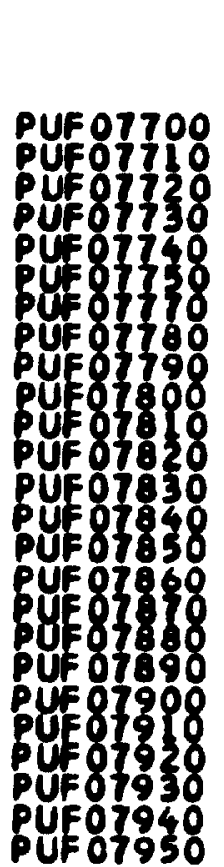


STRIMG:XINTPF + $11=$ SNI

c 1340 CONTIMUE

C

HAITE16.1325! STRING

1342 STRINGinst $=1.105$

C 1345 CONTINUE

\& RESET "SOURCE IN LINE COUNTERN XINTIKKI

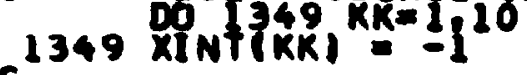

C 1350 contKnUE

C END OF PUFF POSITION PLOT.

1400 CONfINU⿺

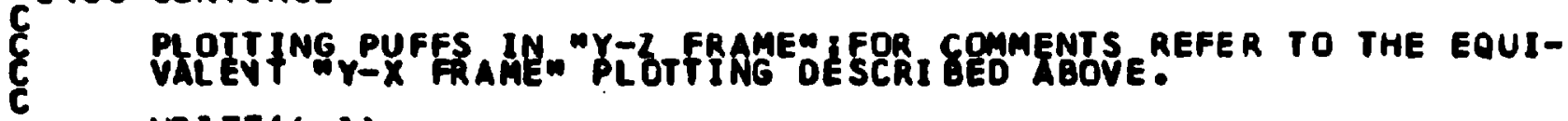

WIF( I $6: 1)$

881

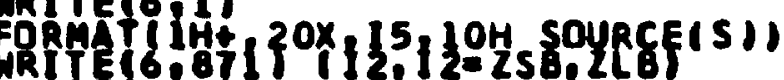

C HFRA 2 ISTRING CONTAINING HORIZONTAL GRID FRAYE DO $1419 N=105$

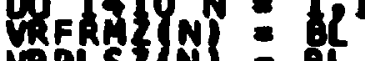

RPLS $=8$

1410

RFRnzin $=$ ot

DO 1418 iff $2=M S 2, N Y 11,10$

NYL $2=1 \mathrm{HF}+4$

1411 OFISI HN $=$ IHFZ,NY 12

HFRM Z IHFZ +5) $=$ SN2

NY $\quad$ \& $M=2+8$

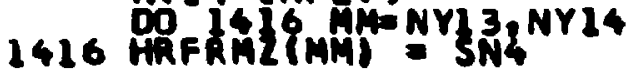




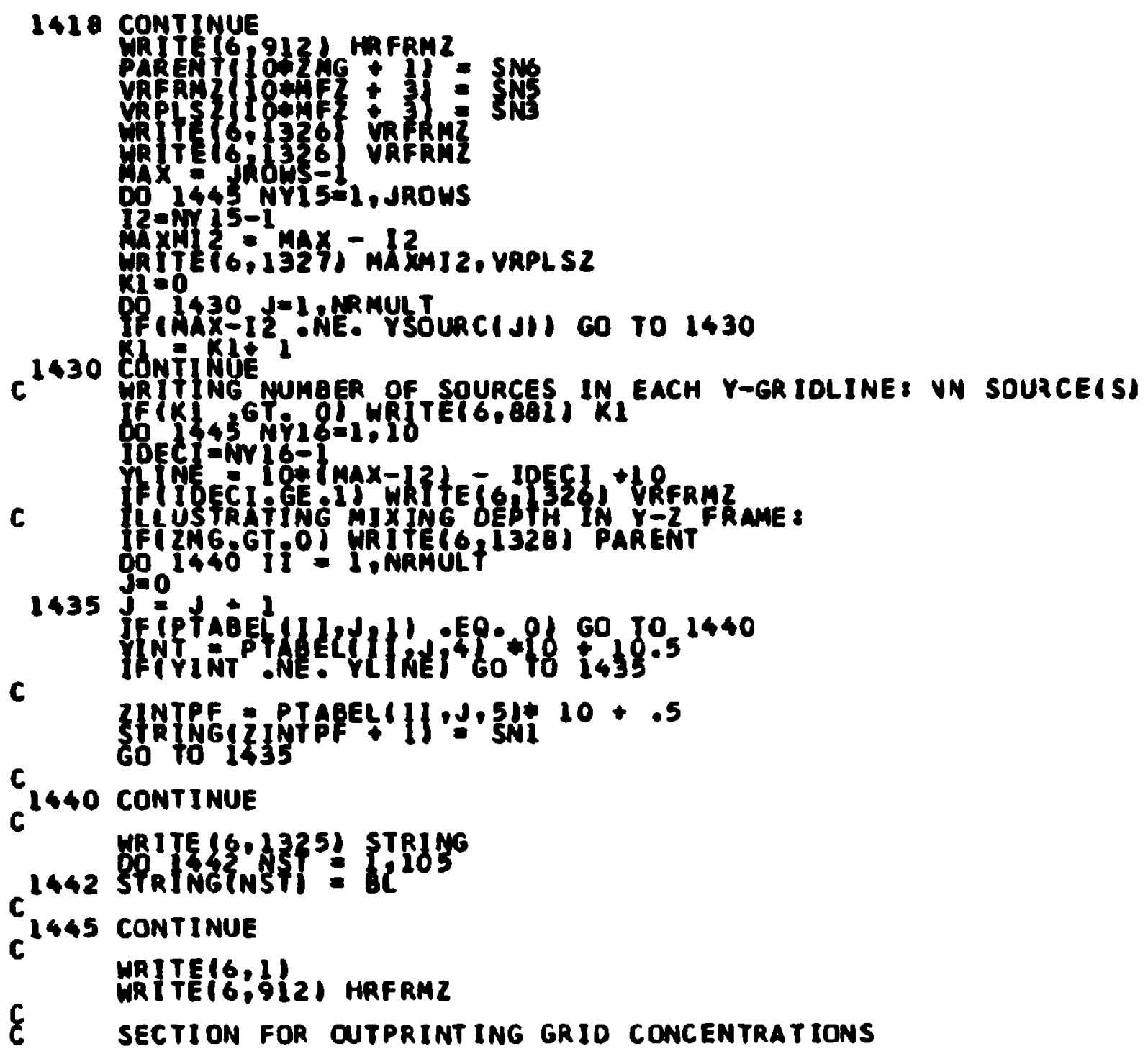

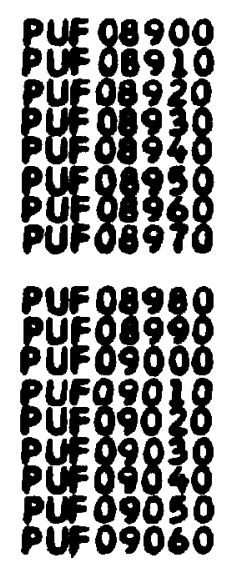

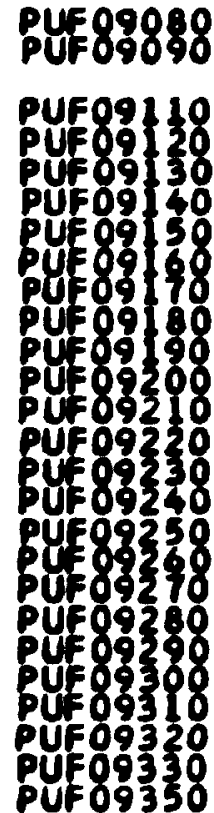


¿ IFIPPING CONCENTRATION PRINTING IF SPECIFIED IN PRIMDA.

C 1510 FORMAT (1HO,49X,37H PRINT OF CURRENT GRID CONCENTRATIONS, /5OX

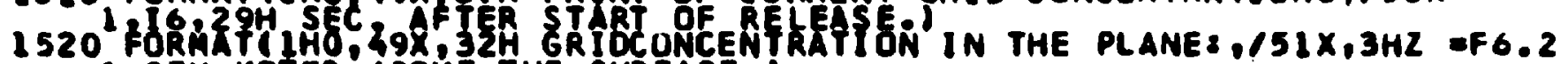
1,25 HETER ABOYE THE SURFACE.I

$c^{152}$

\& LODP THRU ALL 2 LEVELS

MRIIE(6:1301) I TOTIM

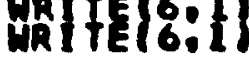

DO 1550 KC=1 KPLANS

OEMKMT $=0$ OEL $2+$ KKC $=-1$

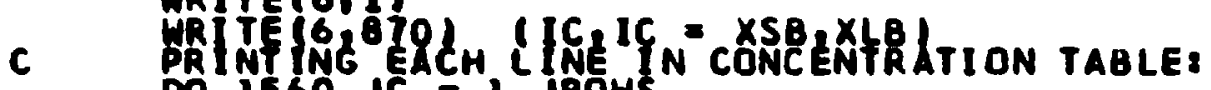

DO 1560 JCA

JjC = JROWS

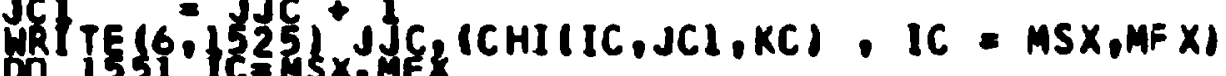

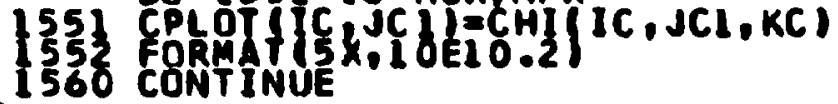

C KC IS THE NO. OF LEYELS PRINTED....HERE CONTROLS WHICH

550 CONKC.EO.1 CALL DRAWICPLOT, 10,17I

WRITE(6:1)

C 60 TO 1600

C1590 FORMATYS5H PUFE POSITION PLOT ANP GRIO CONCENTZATION PKINTING AR 1595 WRITE(6.1590)

C 1600 CONTINUE

C 1600 CONDINGEERIO CONCENTRATION PRINTING SECTION 


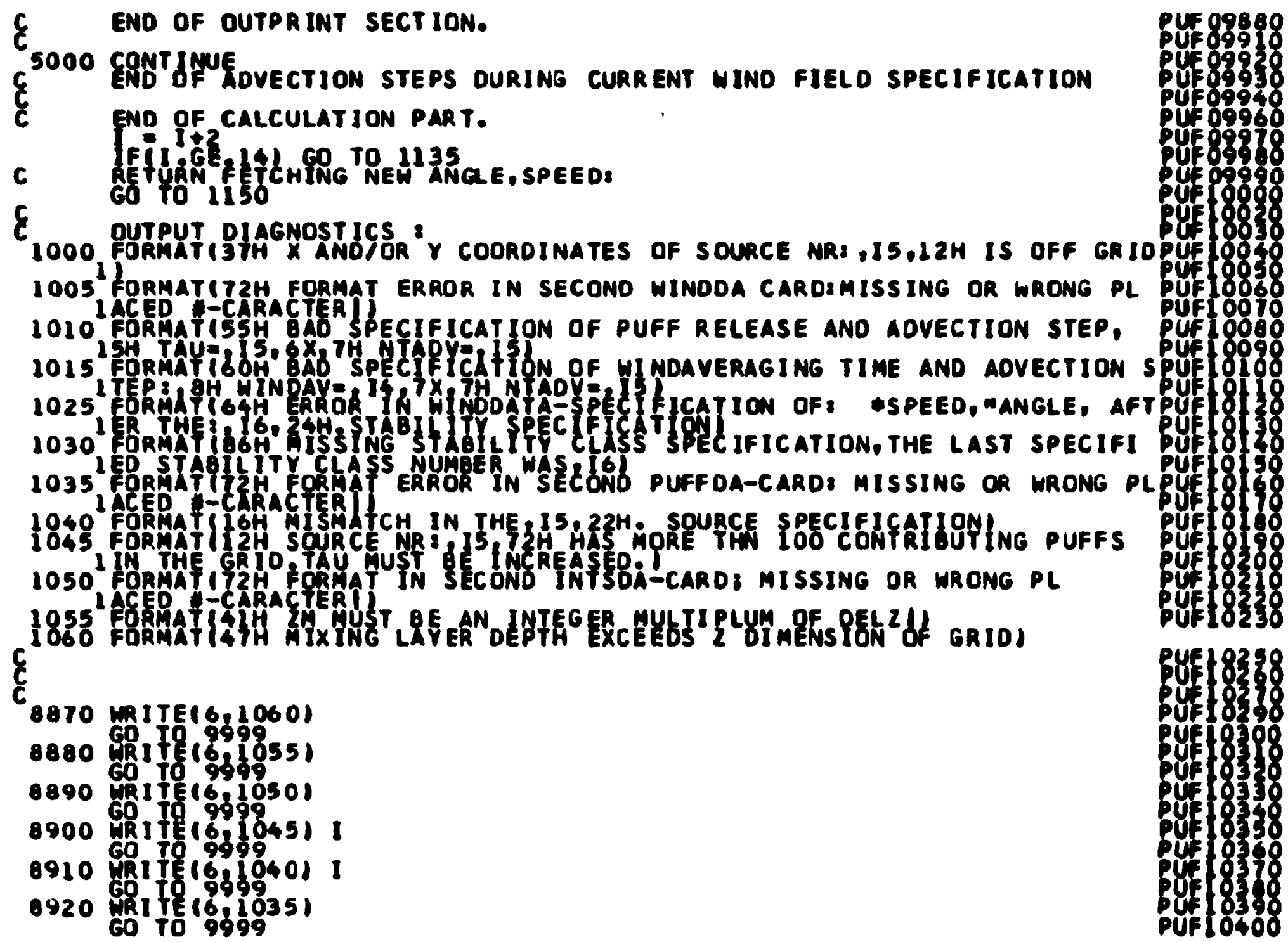




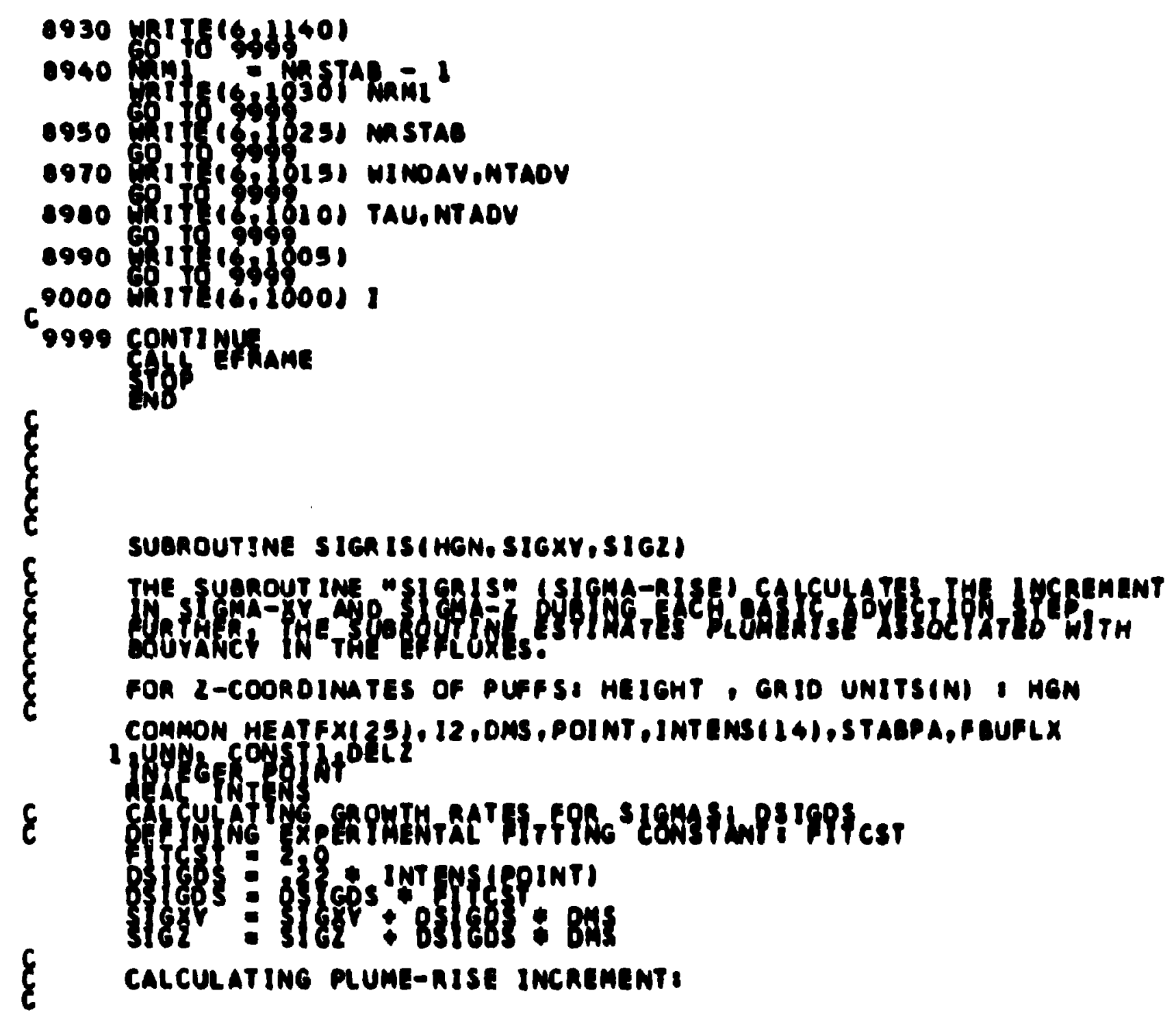



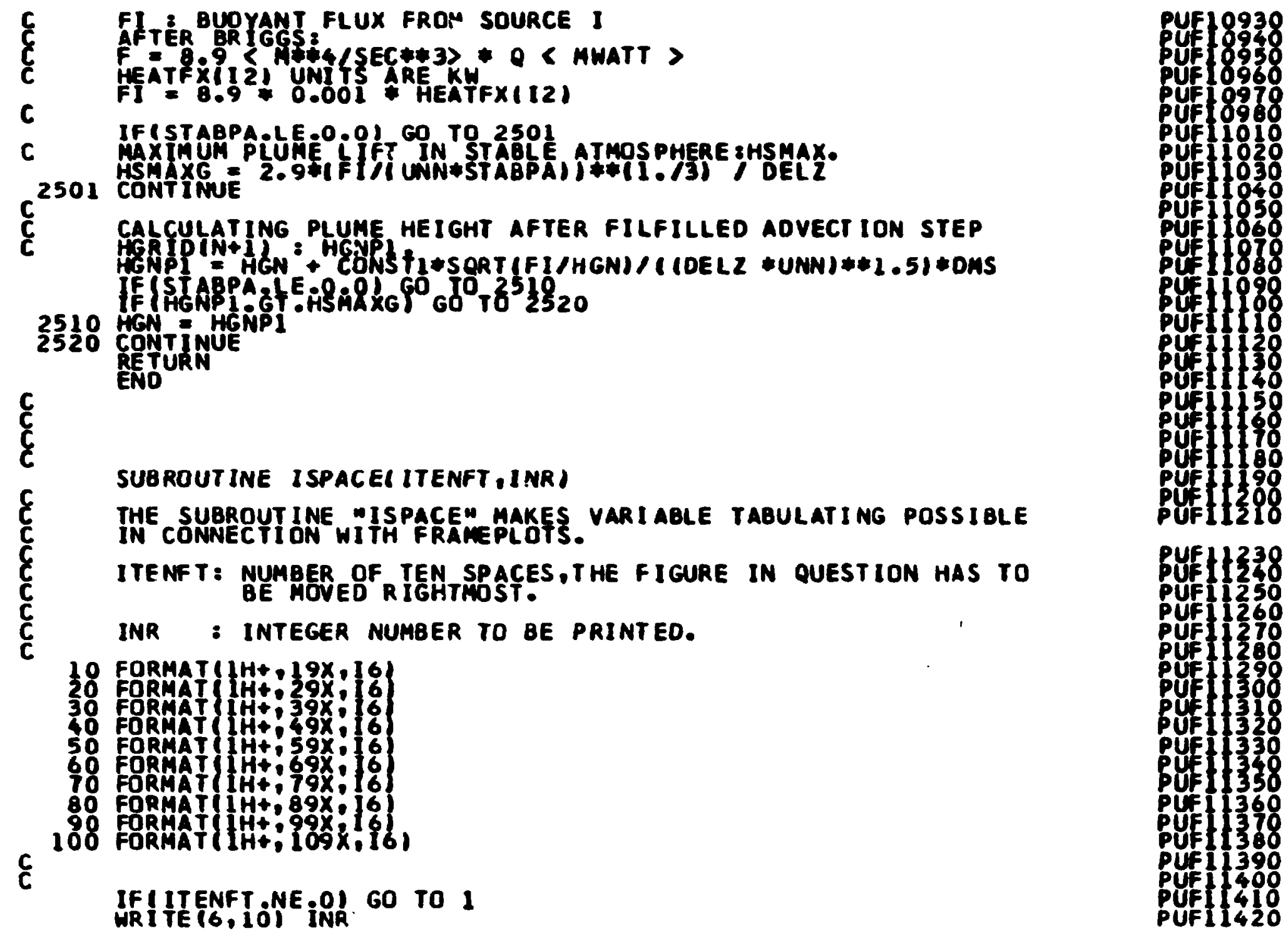


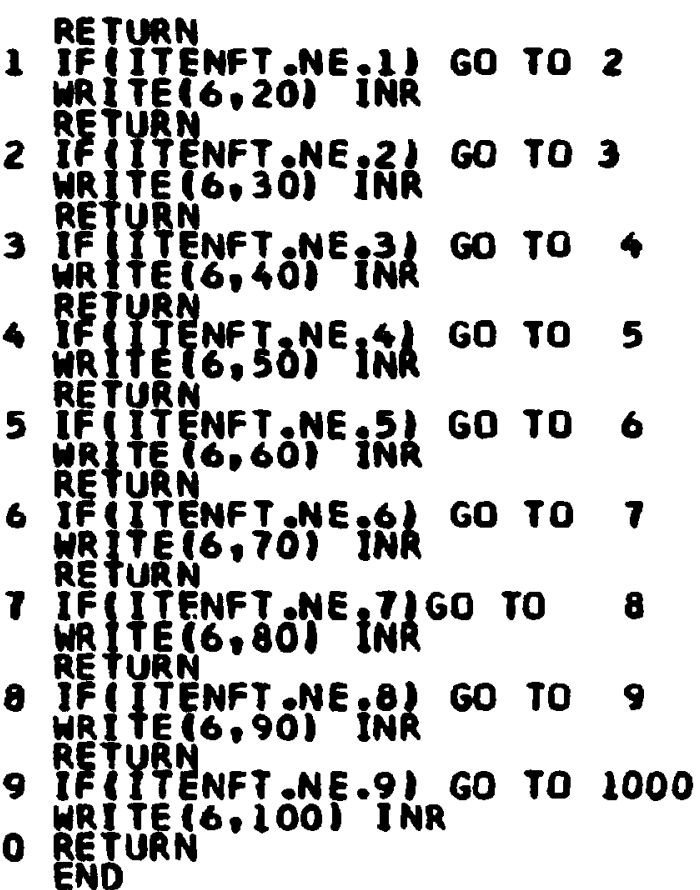

SUBROUTINE JRAH (A,M,N)

IHIS SUBROUTINE CONYERTS THE GRIB CONGENTRATIONS TO LOG VALUES DIMENSION A $(M, N)$

PUF 12430

PUE 11440

PUE 1560

(4)

PUF 1490

puf 1598

puf 1550

PUFII540

PUF 1560

Puf 1588

PUF 1590

UF 11610

PUF $\$ 1638$

PUt 11640

PUE 1660

buf 168

PUF 11690

UfFIII

PUF $117 \div 0$ A. IS THE ARRAY TO BE SMOOTHED AND CONTOURED on $1553 \mathrm{JC}=1, \mathrm{~N}$ Jic $=N-J C$ of 


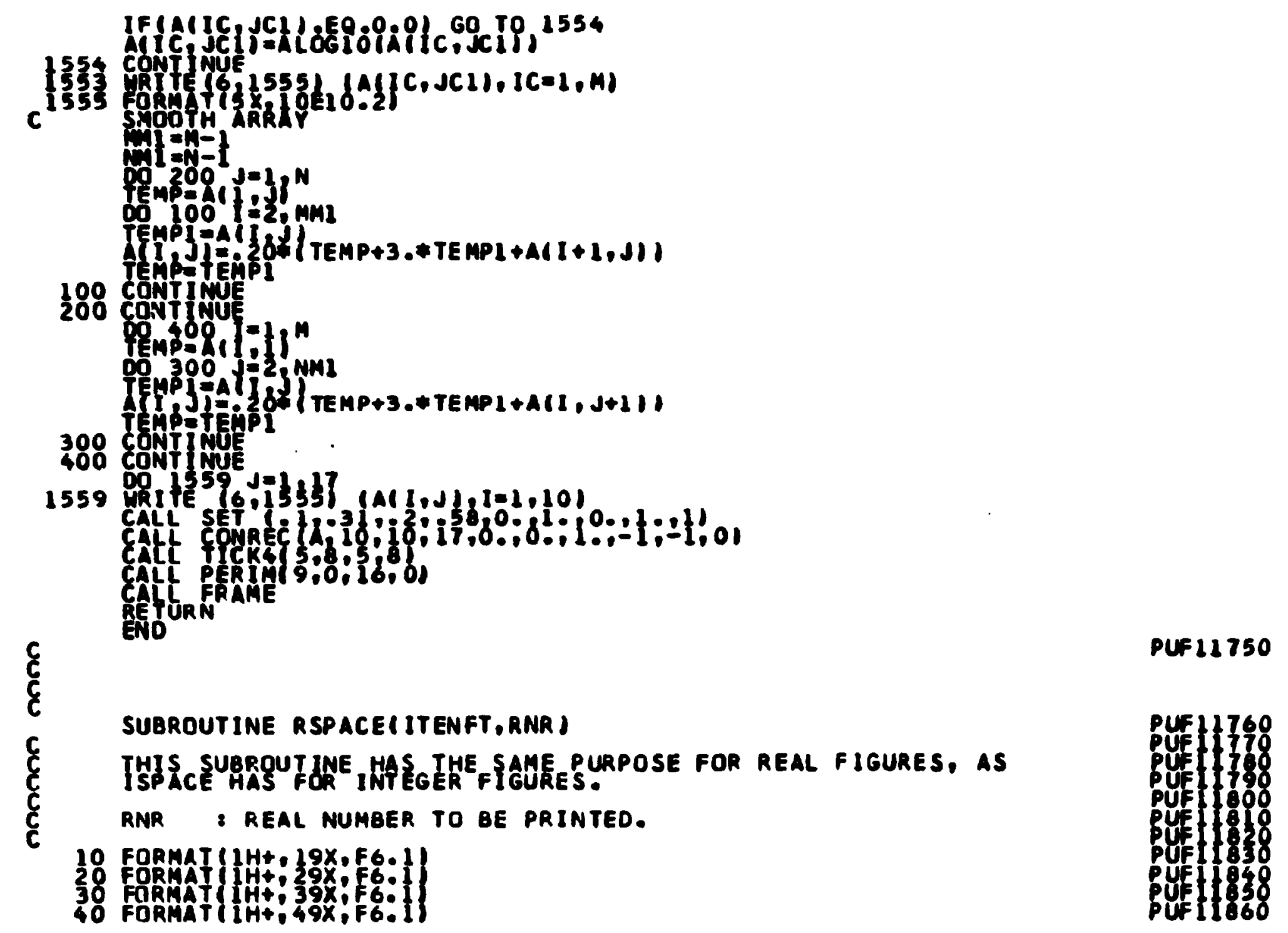



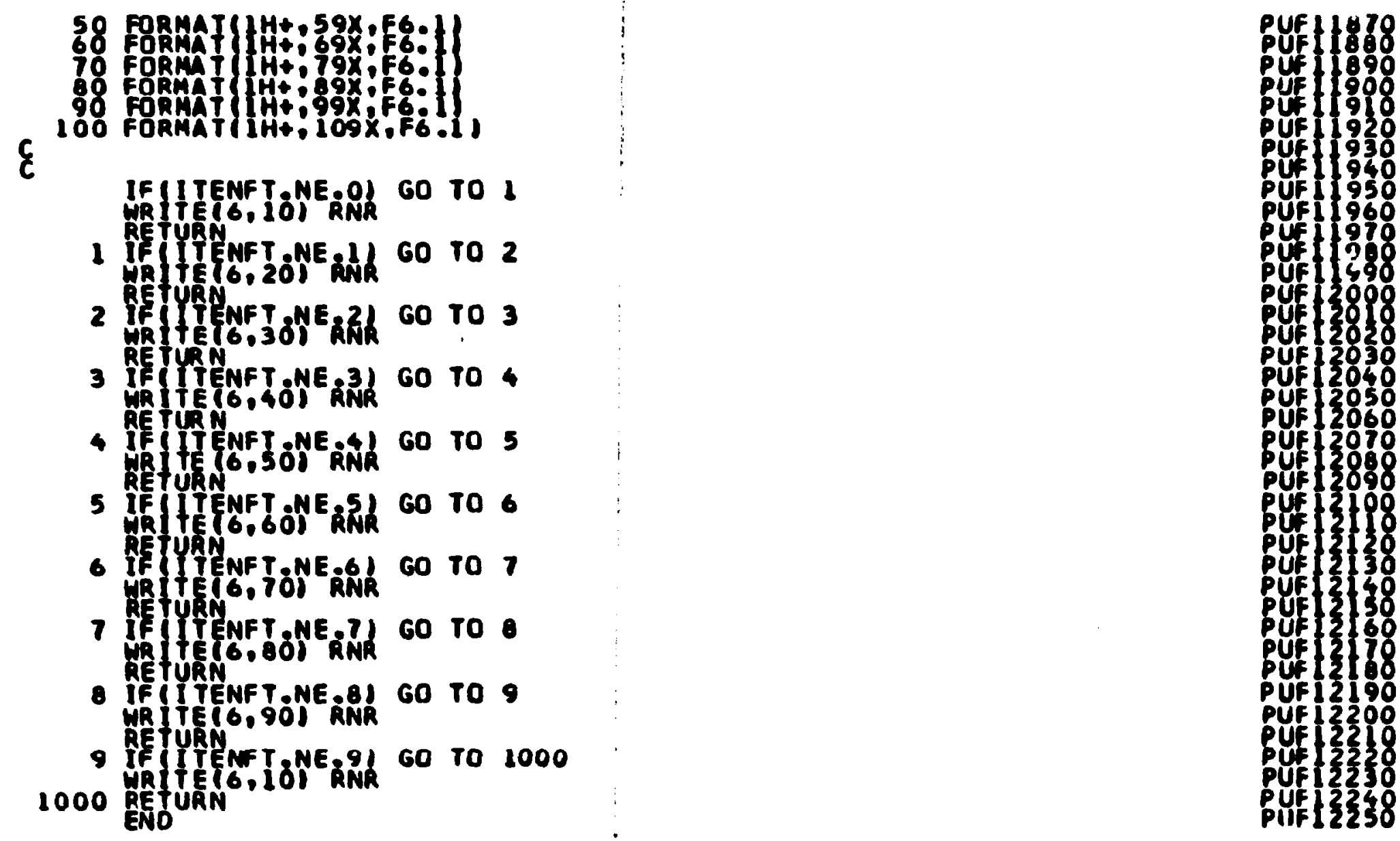
Title and author(s)

Date

October 1982

Description of the Riso puff diffusion model

Department or group

Torben Mikkelsen

Physics Dept.

Group's own registration number (s)

Abstract

The Riso National Laboratory, Roskilde, Denmark, atmospheric puff dispersion model is described. This three-dimensional model simulates the release of Gaussian pollutant puffs and predicts their concentration as they are diffused and advected downwind by a horiiontally homogeneous, time-dependent wind. Atmospheric characteristics such as turbulence intensity, potential temperature gradient, buoyant heat flux and maximum mixing depth have been considered.

Availasle on request from Ris Library, Ris National Laboratory (Ria Bibliotek), Poredgsanleg Risø), DK-4000 Roskilde, Denmark

Telephone: (02) 3712 12, ext. 2262. Telex: 43116 